\title{
A Lexical-Functional Analysis of Predicate Topicalization in German
}

\author{
Gert Webelhuth \\ University of North Carolina at Chapel Hill
}

Farrell Ackerman

University of California at San Diego

In this paper we examine the topicalization paradigm for ten different verbal constructions in German. We argue that a uniform explanation for the observed behaviors follows from the interpretation of the relevant expressions as (parts of) lexical representations. To this end we motivate a revision of Functional Uncertainty as proposed in Kaplan and Zaenen (1989) to account for filler/gap relations in long distance dependencies. We assume with the original formulation of this principle that topicalized elements share values with the (grammatical) function status of an entity an indeterminate distance away. We appeal to the inventory of functions posited within LEXICAL FUNCTIONAL GRAMMAR inclusive of the frequently neglected PREDICATE function, which we argue is associated with both simple and complex predicates. In addition we show that topicalization, given this function-based proposal, should not be limited to maximal categories. We argue that the need to posit a PREDICATE function for German topicalization is supported by an independent line of research within LFG concerning the analysis of complex predicates. For this purpose we employ the proposals of $\mathrm{T}$. Mohanan (1990/1994) which argue for the independence of the construct PREDICATE from its categorial realization. We show that this type of proposal extends to provide a uniform account of the German topicalization paradigm. This permits us to explain the similarities and differences in the behaviors of various sorts of predicators as well as certain idiomatic expressions interpreted as complex predicates. 


\section{Introduction}

German main clauses, as is well-known, require an inflected verb in second position preceded by at most one syntactic constituent. This pattern is exemplified by (1a) where the NP preceding the finite verb hat 'has' is a SUBJECT and in (1b) where the relevant NP is an INDIRECT OBJECT.

(1a) Die Frau hat gestern ihrem Kind einen Ball geschenkt. The woman has yesterday her-DAT child a-ACC ball presented

'The woman gave her child a ball yesterday.'

(1b) Ihrem Kind hat gestern die Frau einen Ball geschenkt. Her-DAT child has yesterday the woman a-ACC ball presented

'The woman gave her child a ball yesterday.'

The preverbal constituents in (1a) and (1b) are standardly analyzed within the German theoretical and descriptive literature as instances of Topicalization. ${ }^{1}$ Such constructions can participate in long-distance dependency relations in which the topicalized element can be separated from its clause mates by another clause. This can be seen below in (2) where the constituent ihrem Kind 'her child', an argument of the embedded verb geschenkt 'give', appears in the matrix clause headed by the inflected verb glaube 'believe' :

(2) Ihrem Kind glaube ich hat gestern die Frau einen Ball geschenkt. her-DAT child believe I has yesterday the woman a-ACC ball presented 'I believe the woman gave her child a ball yesterday.'

Accounts of filler-gap dependencies such as Topicalization have been traditionally formulated within generative approaches in terms of structural properties of phrasal configurations. Kaplan and Zaenen (1989), however, develop a formal apparatus called Functional Uncertainty (FU) which accounts for these dependencies by appealing to the non-structural architectural assumptions responsible for the representation of

\footnotetext{
${ }^{1}$ As observed in Nunberg, Wasow and Sag (1994), the relation between this notion of topic to what is often referred to as the discourse topic in other languages is not always clear. For present purposes we will be content with observing a behavioral similarity between this German entity and the purported topics in other languages, namely that they both are known to participate in long distance dependency relations.
} 
grammatical functions within LEXICAL FUNCTIONAL GRAMMAR (henceforth abbreviated as LFG.)

In this paper we explore the interaction between Functional Uncertainty (henceforth FU) and the topicalization paradigm of ten different German constructions. Although such patterns appear to constitute prima facie problems for the formulation of the proposal presented in Kaplan and Zaenen, we propose that they actually argue for exploiting a grammatical function not assumed in the original formulation of this principle: specifically, we suggest that the proposed repertoire of grammatical functions accessible for the operation of FU should be augmented to contain a PREDICATE function and that this function, contra the categorial assumption contained in the original formulation, can be expressed by a non-maximal category. The claim that such a function is needed for the treatment of German topicalization will be shown to follow from usual assumptions within LFG (see Kaplan 1989) and to derive independent support from crosslinguistic research into the analysis of complex predicates within LFG. The LFG analysis of complex predicates follows the research methodology associated with linguistic theories built around correspondence architectures: in these, primarily lexicalist, theories different domains of grammar are factored into different levels and set in principled correspondence with one another. (Cf. Sadock 1991, Jackendoff 1987, 1997, Bresnan (Forthcoming), Bresnan \& Kanerva 1989, Foley and van Valin 1984, among others.) Most relevantly with respect to the present proposal, it addresses these correspondences between different types of information by raising the issue of lexicality: the work within LFG of Ackerman (1984, 1987), Sells, Zaenen and Zec (1987), T. Mohanan (1990/1994, 1995), Bresnan and Mchombo (1995), Matsumoto (1996), and Ackerman and Webelhuth (1998) directly address the hypothesis that wordhood needs to be analyzed in terms of the interaction between different types of information, found at different levels of representation. It will become evident that German topicalization is explanatorily analyzed in terms of a similar factorization of information for German complex predicates.

Finally, though we formulate our proposal in terms of FU within LFG, it should be understood that we do so because we believe that a function based approach such as this provides an illuminating account of the data. If our adaptation of FU to the explanation of German topicalization is successful, this will provide both an independent indication of the usefulness of function based proposals of long distance dependencies as well as a challenge to structure based proposals to account for the relevant distributions.

The organization of this paper is as follows. In section 2 we present an overview of functional uncertainty as well as relevant aspects of LFG. In addition, we examine how 
it applies to certain instances of German topicalization. Most importantly we show how the topicalization behavior of simple verbs raises questions concerning the tenability of a proposal formulated solely in terms of the standard inventory of grammatical functions. In section 3 we explore the patterns of verbs consisting of a preverb and verbal stem. In section 4 we present the topicalization paradigm for 10 verbal constructions, we formulate a general proposal which addresses the lexicality of all of the predicates and show how this proposal applies to the distributions examined in section 3 .

\section{Functional Uncertainty}

As mentioned previously, LEXICAL FUNCTIONAL GRAMMAR belongs to the class of theories which are lexicalist and level-oriented. The lexicalist commitment means that lexical representations are assumed to be rich data structures: predicators, for example, contain, among other things, information concerning lexical category, lexical semantics, morphosyntactic information such as tense, person-number agreement, etc., valence, and the grammatical function inventory of arguments. This information is contributed to the two levels of representation which play a role in this article: c(-onstituent) structure representations reflect linear precedence and dominance relations and are formalized in terms of tree structure configurations, while $\mathrm{f}(-$ unctional) structures represent the loci of much of the information associated with c-structure elements and are formulated in terms of attribute value matrices.

The basic apparatus of the theory can be illustrated by providing an analysis of the simple English sentence John telephoned Jane. The lexicon of English contains, among other things, lexical representations for the three words in this sentence:

John N, Jane N, .....

telephoned $\mathrm{V}<$ SUBJ, OBJ $>\ldots$.

TNS $=$ PAST

\section{Figure 1}

Within LFG a lexical item such as 'telephone' is lexically associated with the grammatical functions with which it must co-occur in a well-formed sentence. In addition, words are 
assumed to be fully derived and inflected and therefore an entry such as telephoned also carries information concerning the value for the tense attribute (TNS), namely, PAST. In effect, a lexical item such as telephoned projects information into the clause nucleus which it heads. The functional information thus represented is referred to as a f(unctional) structure and technically is represented by a formal object called an attribute value matrix or AVM. It contains attributes such as $\mathrm{REL}^{2}$, grammatical functional names such as SUBJ and OBJ which must be associated with values, and morphosyntactic information such as TNS. The values come from information associated with the actual lexical items that appear in a clause and which are placed in correspondence with the attribute names.

In addition, English contains evidence for phrase structure of the sort in Figure 2: these rules essentially state that English has hierarchical phrase structure and that grammatical functions such as SUBJ and OBJ correspond to positions in the surface configurations of simple sentences.

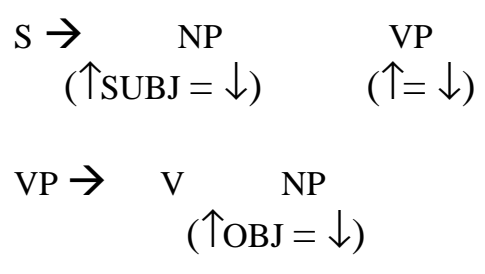

\section{Figure 2}

When lexical entries occupy the terminal nodes of phrasal configurations, we get the cstructure in Figure 3, annotated with grammatical function information, for the sentence under consideration:

\footnotetext{
${ }^{2}$ Those familiar with LFG will note that we have substituted the attribute REL for the standard attribute PRED in all functional structures within this paper. The use of REL as an attribute for the semantic attribute (i.e. RELATION) follows the convention in HPSG [see Pollard and Sag 1994 as well as the revision of LFG found in Andrews and Manning 1993 and Andrews and Manning (In press).] REL is also employed in the semantic structures of LFG (Dalrymple et. al. 1992). Among other reasons, the use of this attribute name permits us to avoid possible confusion between the name PRED and the grammatical function PREDICATE which plays a central role in subsequent discussion.
} 


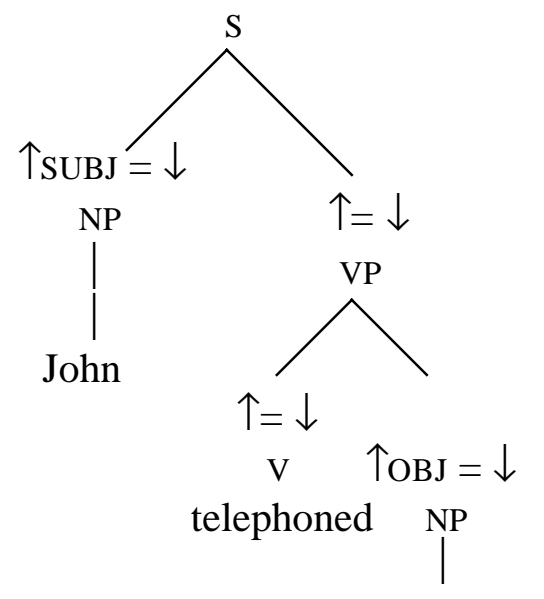

Figure 3

Various principles of the theory regulate the flow of information contained in the cstructure and yield the f-structure representation in Figure 4:

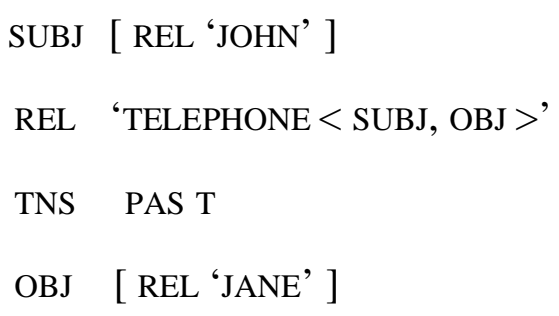

\section{Figure 4}

As can be seen, f-structures contain among their information types information concerning the value for grammatical functions such as SUBJ and OBJ (e.g. in Figure 4 the value for the SUBJ attribute is the meaning supplied by the NP 'John') as well as morphosyntactic information such as TNS. They do not contain categorial information. From the perspective of representational issues, the c-structure and f-structure in English differ with respect to whether the SUBJ and OBJ entities constitute a distinguishable constituent with the verbal element or not: in c-structure the $\mathrm{V}$ and NP/OBJ do represent 
such a constituent, while in f-structure they have no closer relation than that displayed by the $\mathrm{V}$ and NP/SUBJ.

As mentioned previously, Kaplan and Zaenen (1989) develop a means within Lexical Functional Grammar, namely Functional Uncertainty, to account for long distance dependency phenomena such as topicalization. This function based proposal represents a departure both from the original analysis of long distance dependencies within LFG, which was structure-based, as well as from the standard appeal to structure within most generative proposals. To see how this works, consider sentence (3): ${ }^{3}$

\section{(3) Jane, John telephoned}

(3) represents an instance of topicalization where Jane, the TOPIC, is identified with the OBJ argument absent from the c-structure headed by the verb telephoned. The functional structure for sentence (3) is presented in Figure 5:

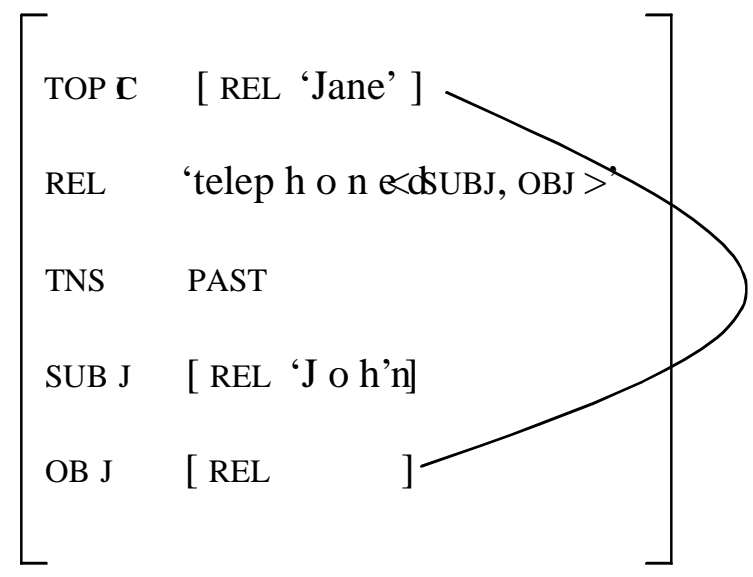

Figure 5

Given the monostratal assumptions of LFG, the "missing" OBJ argument is not represented as a null category in c(-onstituent) or phrase structure, but is rather represented only in the f-structure representation. The line connecting the TOPIC function and the OBJ function argument in Figure 5 indicates that the value for the TOPIC is

\footnotetext{
${ }^{3}$ We convey the essentials of Functional Uncertainty by adapting the exposition found in Dalrymple (1993). It should be noted that though Functional Uncertainty was originally formulated to address long-distance dependencies it has become the basic mechanism for addressing anaphora (Dalrymple 1993) and multiple case marking or 'Suffixaufnahme' in Australian aboriginal languages (Nordlinger 1998).
} 
identical to the value for the OBJ attribute: they both have the value 'Jane'. In other words, the TOPIC function supplies the value for some grammatical function which would otherwise have none: given that a common sense principle in the theory demands that all functions associated with an argument taking entity must have a value, the OBJ function must bear a relation to some nominal in order for the sentence to be well-formed. In the present instance the OBJ is an argument of the matrix predicate and therefore bears a fairly 'local' relationship to the TOPIC. On the other hand, the TOPIC can provide a value for a non-local argument as in (4):

(4) Jane, Henry claimed that Bill said that John telephoned.

In (4), which consists of three clause nuclei, the TOPIC 'Jane' corresponds to an OBJ argument embedded two clauses deep. The relation between the TOPIC and OBJ is represented by the f-structure in Figure 6:

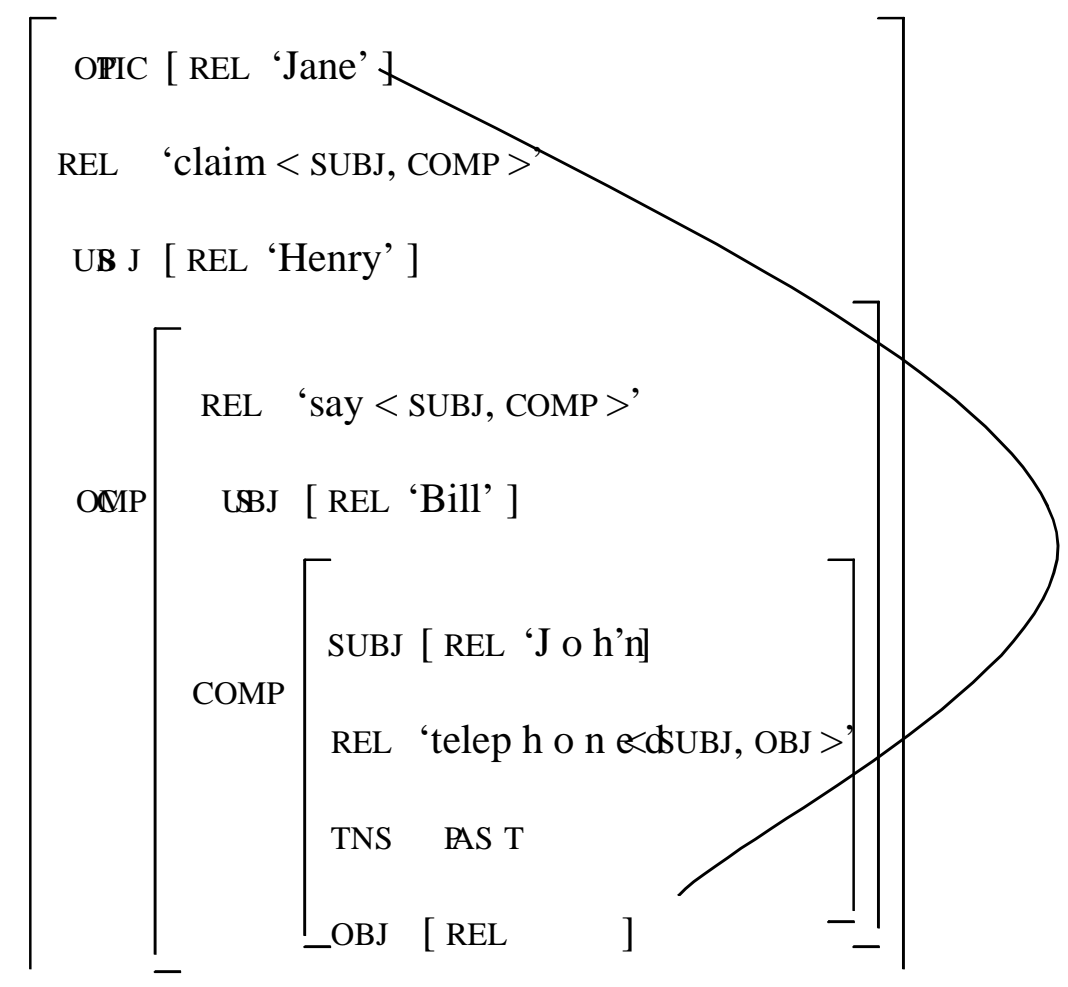

Figure 6

As in the f-structure for sentence (3), the line conveys that the missing value of the OBJ attribute - this time two clauses deep - is identified with the value for the TOPIC. In this 
way all of the attributes in the f-structure have values and the f-structure as a whole is well-formed.

In sum we have seen that FU provides a principled way to define paths through attributes in functional structures (i.e., attribute-value matrices) in order to identify the values between a known attribute and an attribute whose value needs to be determined.

Functional Uncertainty, as developed in Kaplan and Zaenen (1989), is a principle constraining the relation between fillers and gaps of the type illustrated above. Dalrymple (1993:114) suggests that with Functional Uncertainty "an infinite disjunction of possibilities is encoded in finite terms..." Zaenen and Kaplan propose the following schema:

\section{Schema for Functional Uncertainty (= FU)}

$$
\begin{aligned}
& S^{\prime}-->>\quad \Omega \quad \Sigma \\
& (\uparrow \mathrm{DF}=\downarrow) \\
& (\uparrow \mathrm{DF})=\left(\downarrow \text { BODY}^{*} \text { BOTTOM }\right)
\end{aligned}
$$

Where DF $=$ discourse function, the values for Body and Bottom is some (set of) $\mathrm{GF}(\mathrm{s})$ and $\Omega=\mathrm{XP}$ and $\Sigma=\mathrm{S}$. $^{4}$

\section{Figure 7}

Essentially, this schema requires that the value of a maximal phrasal category bearing a discourse function, e.g. TOPIC, be identified with the value for a grammatical function (GF) attribute of some element (= Bottom) an indeterminate distance away (= Body*). Parametrization of languages with respect to differences in extraction domains and/or the value of extracted elements is localized, respectively, in the values provided for Body and Bottom. Kaplan and Zaenen assume the standard set of grammatical functions within LFG: SUBJ, OBJ, OBL, XCOMP, COMP, RELMOD, ADJ. Given this formulation, the appropriate schematic representation needed for (4) will be something like the following:

$$
(\uparrow \text { Topic })=(\uparrow \text { Comp } * \text { Obj })
$$

In other words, 'Jane' is identifiable simultaneously as the value for both the TOPIC function and the OBJ function as it is traced through a path consisting of an indeterminate

\footnotetext{
${ }^{4}$ Though we speak here generally about DF, it should be understood that we are only making claims about the DF referred to as TOPIC.
} 
number of COMPS. Functional Uncertainty encodes, therefore, a many-to-one function of attributes into a single value.

Having outlined the key elements of this function based proposal, we turn to the basic problem addressed in this paper, namely, German topicalization. Certain German patterns of topicalization seem to present a challenge to FU as formulated above. Consider the patterns of topicalization presented in (5a) - (5e).

(5a) Die Frau hat gestern ihrem Kind einen Ball geschenkt. the woman has yesterday her-DAT child a-ACC ball presented 'The woman gave her child a ball yesterday.'

(5b) Ihrem Kind hat gestern die Frau einen Ball geschenkt. her-DAT child has yesterday the woman a-ACC ball presented 'The woman gave her child a ball yesterday.'

(5c) Einen Ball hat gestern die Frau ihrem Kind geschenkt. a-ACC ball has yesterday the woman her-DAT child presented 'The woman gave her child a ball yesterday.'

(5d) Geschenkt hat gestern die Frau ihrem Kind einen Ball. presented has yesterday the woman her-DAT child a-ACC ball 'The woman gave her child a ball yesterday.'

(5e) Geschenkt glaube ich hat gestern die Frau ihrem Kind einen Ball. presented believe I has yesterday the woman her-DAT child a-ACC ball 'I believe the woman gave her child a ball yesterday.'

Whereas nominal expressions (NPs) bearing various grammatical functions (SUBJ, IO, OBJ) precede the verbal element hat in (5a-c), there is a verbal element in this position in $(5 \mathrm{~d})$ and (5e). The difference between (5d) and (5e) consists solely in the fact that the verbal element in (5e) appears at a remove of two clauses from the gap site. (5e) is consequently parallel to (2) above. In general we see that verbal elements behave like nominal elements with respect to topicalization. This similarity raises two specific problems with respect to the formulation of FU: (i) if, as we will assume, these verbal elements are lexical categories, they challenge the hypothesis that only maximal categories participate in long distance dependencies and (ii) the lexical categories serving as semantic heads of clauses in LFG do not bear any of the grammatical functions hypothesized to be accessible by FU. In particular, the latter issue raised by these phenomena with respect to FU for $(5 \mathrm{e})$ is what value to assign to the variable ' $\mathrm{x}$ ' for ВОттОМ in the following equation: 


$$
(\uparrow \text { Topic })=(\uparrow \text { COMP } x)
$$

The presence of the COMP taking matrix predicate glaube 'believe' in (5e) makes it reasonable to posit a filler/gap path through the COMP function. On the other hand, it is unclear how best to characterize the relevant path or BODY in the representation of both the subordinate clause in $(5 \mathrm{e})$ and the main clause in $(5 \mathrm{~d})$ :

$$
(\uparrow \text { Topic })=(\uparrow ? \mathrm{x})
$$

In other words, we are confronted by the issue as to how to interpret the presence of auxiliary elements such as hat 'has' in compound tense constructions. Though these have been frequently interpreted as matrix predicates with VP complements bearing the XCOMP in LFG (cf. Falk 1984), there is an alternative analytic tradition within this framework according to which the auxiliary and a verb it supports together constitute a complex predicate which corresponds to a single clause nucleus [see K.P. Mohanan 1982, Ackerman 1984, 1987, Butt et. al. 1996, and the recent X-bar theory of LFG reviewed in Bresnan (Forthcoming).]

In sum, the original formulation of Functional Uncertainty seems both categorially and functionally inadequate to address constructions such as (5d) and (5e). In addition, it presumes a standard analysis of auxiliaries which we will argue is problematic.

A straightforward solution to these two problems would be to propose that (1) the maximal category condition on Functional Uncertainty is incorrect and (2) that the inventory of accessible grammatical functions generally appealed to is inadequate. Both of these claims have been independently motivated within the LFG literature and both have found recent formulation in the work of T. Mohanan (1995) on Hindi complex predicates involving nominal incorporation. We turn now to a brief discussion of her proposal in order to convey the relevant distinctions.

It has been a foundational analytic assumption within LFG (as well as Relational Grammar) that grammatical function status is independent of surface expression (cf. Bresnan (1982) among others). This assumption has played an explanatory role in the analysis of noun incorporation (Simpson 1983, Ackerman 1987, among others) and pronominal incorporation yielding so-called pro-drop effects (Grimshaw 1982, Bresnan and Mchombo 1987, among others). In particular, it has been argued that phrasal categories, lexical categories, clitics, and affixes can all bear grammatical functions. For 
the sake of concreteness we illustrate this assumption by providing an overview of $\mathrm{T}$. Mohanan's proposal of Hindi incorporation.

T. Mohanan (1990/1994) provides evidence for the claim that Hindi possesses an incorporation construction in which a nominal and a verb represent a morphological compound from the perspective of what she refers to as grammatical category structure (i.e. categorial expression) structure. On the other hand, she also adduces evidence to show that the incorporated nominal bears the grammatical function OBJ in what she refers to as grammatical function structure. In other words, the lexical category $\mathrm{N}$ bears the function OBJ: that is, non-maximal categories are assumed to bear grammatical functions. ${ }^{5}$ The full factorization of noun incorporation into different levels of information can be illustrated with the representation for kitaabeõ beciôî̃ 'book -sold', where the levels relevant for the present purpose are boldfaced:

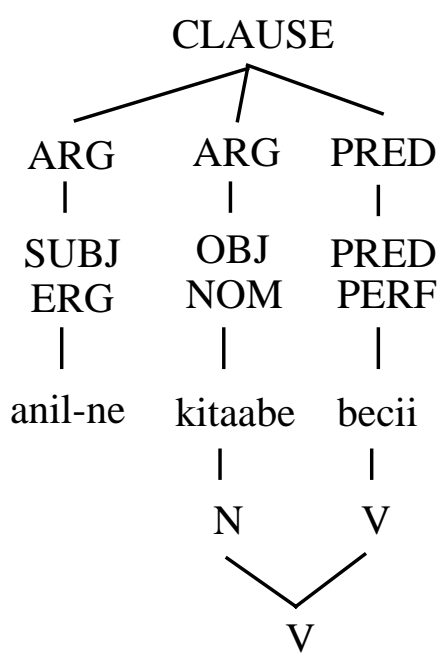

\section{Figure 8}

As can be seen, whereas the $\mathrm{N}$ and $\mathrm{V}$ constitute a morphological word in GRAMMATICAL CATEGORY STRUCTURE, specifically a $\mathrm{V}$, the lexical category $\mathrm{N}$ is construed as an argument bearing the OBJ function in relation to the $\mathrm{V}$.

Since analyses of several different phenomena in this framework assume that grammatical functions are not necessarily associated with a maximal category it is reasonable to adopt this assumption in addressing the German topicalization paradigm. In

\footnotetext{
${ }^{5}$ This is based on empirical evidence whereby the OBJ argument and the verb agree for gender and number, when the OBJ bears no overt case-marking and the SUBJ is marked with the ERGATIVE case. The operative assumption is that verbs agree with entities bearing syntactic relations to them, irrespective of whether the elements bearing this relation are independent elements in c-structure or internal pieces of compounds.
} 
particular, an emendation of FU to the effect that functions can be accessed independent of maximal phrasality appears to be independently motivated for an optimal analysis of noun incorporation on Mohanan's account. So, we will assume that the maximal phrasality assumption for Functional Uncertainty represents a parametric difference between languages in much the same way that constraints on the value of both the Body and Bottom can vary among languages.

\section{Schema for Functional Uncertainty (Revision 1)}

$$
\begin{array}{ccc}
\mathrm{S}^{\prime}--->\quad & \Omega & \Sigma \\
& (\uparrow \mathrm{DF}=\downarrow) \\
& (\uparrow \mathrm{DF})=(\downarrow \text { BODY* BOTTOM })
\end{array}
$$

Where $\mathrm{DF}=$ discourse function, the values for Body and Bottom is some (set of) $\mathrm{GF}(\mathrm{s})$ and $\Omega=\mathrm{XP}$ or $\mathrm{X}$, and $\Sigma=\mathrm{S}$.

\section{Figure 9}

We turn now to the second revision of Functional Uncertainty which seems to be necessitated by the German data, namely, we expand the set of accessible grammatical functions. This too yields greater flexibility with respect to parameterizing differences between languages in that different languages can access different functional distinctions. First of all in connection with this proposal it should be noted that the PREDICATE is, from a formal perspective, regarded as a grammatical function within standard LFG (see Kaplan 1989). On the other hand, there has generally been little empirical motivation provided for the need to appeal to this function on the basis of grammatical phenomena. Mohanan (1990/1994), however, is among several linguists who have explicitly argued for the explanatory value of this function.

Mohanan demonstrates that in Hindi certain complex predicate constructions are categorially indistinguishable from one another. On the other hand, they are functionally distinct. In particular, she contrasts complex predicates such as prasĖamsaa kar 'praise' with yaad kar 'remember'. She distinguishes these predicates on the basis of such behaviors as whether the verb kar 'do' can exhibit agreement with the co-occurring nominal prasĖamsaa 'praise' vs. yaad 'memory': agreement occurs with the former, but not with the latter. She argues that such behaviors argue for the factorization of complex predicates into distinct levels of information in correspondence with one another. The two levels utilized in her analysis are argument structure and grammatical category structure. 
From a categorial perspective, both complex predicates are argued to be phrasal expansions, in contrast to the sort of lexical entities represented by the incorporation constructions reviewed previously. The two complex predicates can be represented as follows (adapted from T. Mohanan (1990/1994):

prasĖamsaa kar 'praise':

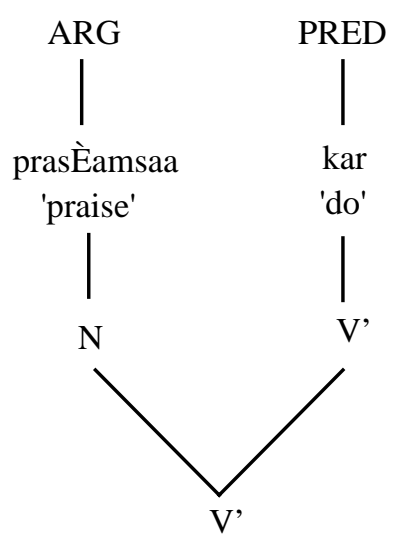

Figure 10

yaad kar 'remember':

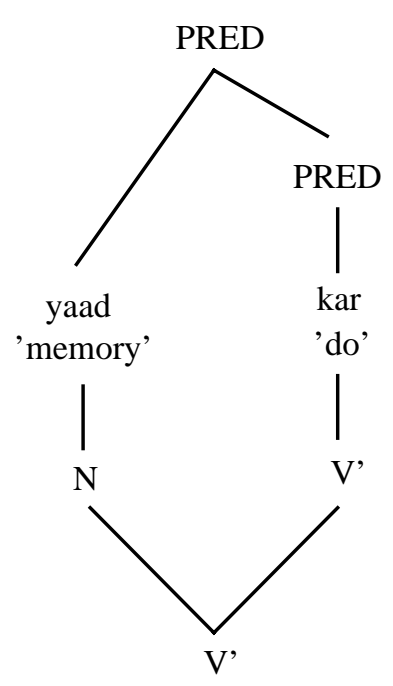




\section{Figure 11}

It is important to observe that these constructions are minimally distinct. They differ with respect to what is considered to be the PREDICATE: whereas the PREDICATE is limited to the embedded V' in 'praise', it spans both elements of the outer V' in 'remember'.

Mohanan observes a particular restriction on sentential negation with the negative word nahî̃ĩo, 'no/not'. She proposes the following condition on its distribution in order to account for its different interaction with these predicates:

In sentential negation:

(A) NEG is attached to the left of the verb in GC STR;

(B) NEG must be adjacent to the PRED in ARG STR/GF STR.

These conditions account for the following distributions:

$$
\begin{aligned}
& \text { anil-ne ilaa-ko [yaad] nahîõĩõ [kiyaa] } \\
& \text { Anil-E(M) Ila-ACC(F) memory-N(F) not do-PERF.M }
\end{aligned}
$$

'Anil didn't remember Ila'

anil-ne ilaa-ko nahîõĩ [yaad kiyaa]

Anil-E(M) Ila-A(F) not memory-N(F) do-PERF.M

'Anil didn't remember Ila'

(7a) anil-ne ilaa-kii [prasĖamsaa] nahîôĩo [kiyaa]

Anil-E(MA) Ila-G(F) praise-N(F) not do-PERF.M

'Anil didn't praise Ila'

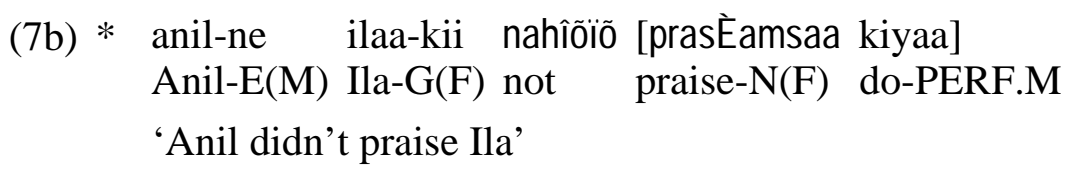

As can be seen, the negative element nahiôiõ appears immediately before the $\mathrm{V}$ in the (a) sentences, in accordance with condition (A). In contrast, condition (B) permits this element to additionally appear before yaad in the complex predicate yaad kar in (6b), since the $\mathrm{N}$ and $\mathrm{V}$ together constitute the PREDICATE (see Figure 2). Nahîoĩo cannot appear before prasĖamsaa in prasĖamsaa kar 'praise' in (7b), since the $\mathrm{N}$ in this construction is interpreted as an ARG (see Figure 11). 
It is important to note that, on Mohanan's account, conditions on the distribution of the negative word in Hindi appear to require an accessible notion of PREDICATE: in effect, the negative word can appear before the PREDICATE of the clause. The crucial aspect of this proposal for our analysis of German is that two syntactically independent elements can jointly represent the PREDICATE or one of the pieces can represent the PREDICATE in ARG STRUCTURE. Mohanan's analysis provides support from Hindi for the functional theoretical construct PREDICATE which will play an explanatory role in the present account of German topicalization.

In summary, we see that there is independent motivation from the analysis of Hindi complex verbal forms to assume that (i) grammatical functions can be borne by lexical categories and (ii) there is a need to recognize a PREDICATE function distributed over syntactically independent elements constituting a phrase. These conclusions can be straightforwardly applied to the German topicalization phenomena we have encountered so far. ${ }^{6}$

We will assume that the topicalized elements in (5d) and (5e) are lexical categories that bear the grammatical function PREDICATE. In other words, the revision of FU proposed to address the German data simply deploys some independently motivated assumptions for the analysis of complex predicates within LFG. The relevant representation for (5d) would accordingly be as in Figure 12.

Geschenkt hat gestern die Frau ihrem Kind einen Ball. presented has yesterday the woman her-DAT child a-ACC ball

'The woman gave her child a ball yesterday.'

\footnotetext{
${ }^{6}$ It should be observed that the pieces of complex predicates that are topicalizable in Hindi appear to be the mirror-image of what is topicalizable in German. We will ignore this intriguing fact in the present paper.
} 


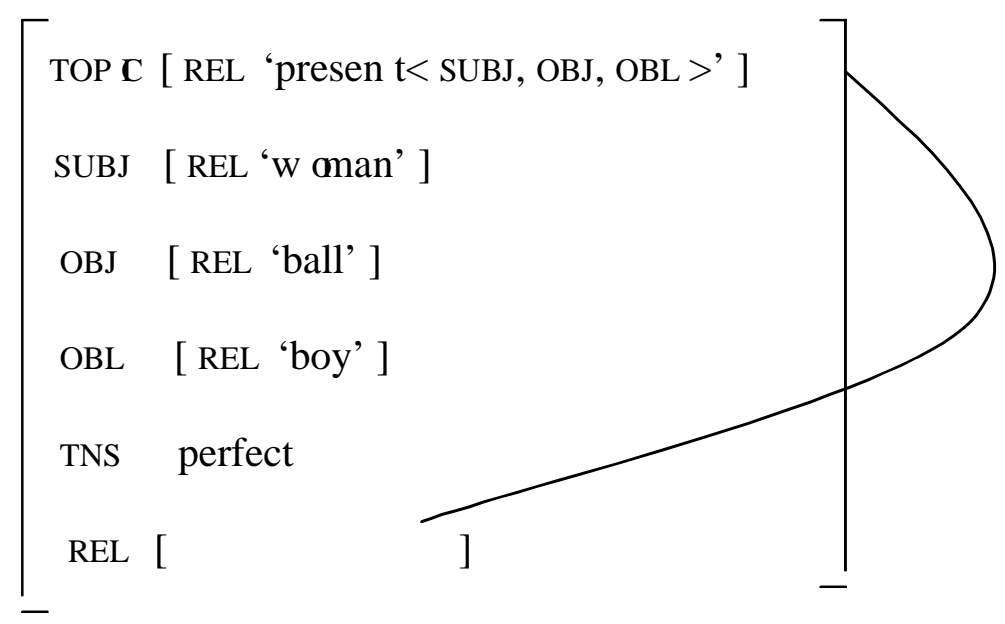

$\underline{\text { Figure } 12}$

The preceding f-structure contains the two revisions discussed above, namely, a lexical category, i.e. geschenkt, supplies a value for the new function PREDICATE. There is an observable difference between the categorial composition of sentence (5d) and the preceding f-structure: whereas its constituent structure contains the verbal auxiliary hat which bears agreement and tense values for the clause, this information is interpreted as information associated with a single clause nucleus headed by the PREDICATE 'present'. In other words, the auxiliary hat does not define its own clause nucleus as it would if it were analyzed as a raising predicate taking geschenkt as a mere syntactic complement of some sort. It will be argued below that there is a lexical as well as a syntactic dependency between an auxiliary such as hat and a participle such as geschenkt. Indeed, we will argue that different lexically composed complex predicates in German all share similar behaviors with respect to topicalization.

The claim that assumptions bearing on the treatment of complex predicates are relevant for the explanation of these data of course raises the question as to whether there are other data which seem problematic for the original formulation of FU and whether these too are amenable to an analysis in terms of complex predicates. It also raises the question as to what independent motivation there might be for regarding the relevant entities as complex predicates. In the remainder of this paper we therefore examine several other ostensibly problematic instances of topicalization and demonstrate how an analysis in terms of complex predicates satisfactorily extends to account for them. Moreover we argue that an application of standard FU wherever formulable fails to treat all of the cases as a unitary phenomenon. We will conclude by showing how our proposal extends to the treatment of idiomatic vs. non-idiomatic VPs. 


\section{Complex Predicates with Preverbs ${ }^{7}$}

Before discussing topicalization itself, we first introduce three verbal constructions consisting of a preverbal morpheme (PV) and a verb (stem) i.e. [ PV V ]. In type $1 \mathrm{PV} \mathrm{V}$ constructions the PV is inseparable from the V, while in types 2 and 3 the PV and $\mathrm{V}$ are separable from one another. All three types participate in processes generally regarded as diagnostic of entities with lexical representations, i.e. they exhibit lexical semantic changes, valence changes, case government changes and grammatical function changes, while their participation in derivational operations argues for their having a morphological status.

The separable PV V constructions are central to the claim that all of the complex predicates investigated here have lexical representations: German contains a large number of constructions which must be treated as lexical compositions independent of the syntactic separability of their components. If we can establish that lexical representations must be associated with separable PV V complex predicates this will entail that some lexical representations can be expressed by multiple independent elements in syntax. This conclusion will license the extension of this assumption to certain auxiliary verbs and verb stems which exhibit lexical effects such as grammatical function changes (e.g. passive and causative) and then to compositions consisting of an auxiliary verb and some other category which yield neither lexical semantic effects nor grammatical function changes (e.g. compositions containing modal and aspectual verbs). Throughout, we argue that all of these compositions represent (complex) predicates, i.e. they jointly constitute the functional head of the clauses within which they are contained. In Ackerman and Webelhuth (1998) we refer to constructions which have lexical representations, irrespective of whether they are expressed in surface syntax by a single word or multiple independent words, as lexical combinatorial items, since these entities are lexical and their lexical representations allow them to specify which other combinatorial items they need to combine with in order to saturate their valence. The lexical combinatorial items at

\footnotetext{
${ }^{7}$ As observed by a reviewer preverbs are typically referred to as particles or verb particles in the literature on German. This reviewer also correctly notes that the term preverb provides a somewhat misleading notion of the possible linear position of these elements relative to the verb. While acknowledging this drawback, we will still employ the term since it is commonly used for similar phenomena in research on Uralic, IndoEuropean, Amerindian languages, Caucasian languages, and Australian languages. The German constructions can therefore be seen as a variant of a cross-linguistically widespread phenomenon.
} 
issue have the functional status of PREDICATES. It is the uniform treatment of the disparate set of constructions examined here as complex predicates which will facilitate an explanatory analysis of German topicalization.

\subsection{Three Preverb-Verb Combinations}

\subsubsection{Type 1}

In the first of these constructions, the preverb and the verb (stem) are never separable. Thus, in subordinate clauses the preverb immediately precedes the verb:

$$
\begin{aligned}
& \text { weil sie das Kind er-zog. } \\
& \text { because she the child up-brought } \\
& \text { 'because she brought the child up.' }
\end{aligned}
$$

In declarative main clauses where the finite verb must be in the second position of the clause, the preverb appears with the verb stem in second position (8b) while the verb stem cannot occupy this position alone (8c):

Sie er-zog das Kind t. she up-brought the child

'She brought up the child.'

(8c) * Sie zog das Kind er t.

'She brought the child up.'

\subsubsection{Types 2 and 3}

The second and third types of PV V collocations that we introduce at this point behave alike in the two environments we have just discussed, namely in subordinate clauses and main clauses without topicalization. They additionally evince another similarity which distinguishes them from the previous class: whereas word stress falls on the verbal stem in the previous compositions, it is associated with the preverb in the second and third type. As will be shown in detail later, the motivation for distinguishing between Type 2 and 3 is that they behave differently with respect to topicalization in main clauses. 
Both an=rufen 'call up' and an=kommen 'arrive' are Type 2 collocations, ${ }^{8}$ while auf=machen 'make open' and hoch=heben 'lift up' exemplify Type 3. In both types the preverb and the verb (stem) have to be adjacent in subordinate clauses (in this respect they behave just like Type 1):

(9a) weil er die Frau an=rief. because he the woman up-called 'because he called the woman up.'

(9b) weil er das Fenster auf=macht. because he the window open-makes 'because he opens the window.'

In main clauses, however, the verbal stem (with the inflection) must be separated from the PV: the V occurs in the second position, while the V must remain at the end of the sentence:

(10a) Er rief die Frau an $\mathrm{t}$. he called the woman up 'He called the woman up.'

(10b) Er macht das Fenster auf t. he makes the window open

'He opens the window.'

(11a) * Er an=rief die Frau t. he up-called the woman

'He called the woman up.'

(11b) * Er auf=macht das Fenster t. he open-makes the window

'He opens the window.'

\subsection{German Separable and Inseparable Preverbs}

Thus far we have seen that German contains complex predicates consisting of both separable and inseparable preverbs. This classification of the PVs focuses on their

\footnotetext{
${ }^{8}$ The following diacritics are employed: "-" corresponds to inseparable preverb, and "=" corresponds to separable preverb. In line with the remarks of a reviewer, the distinction between Types 2 and 3 represents a sort of expository convenience based on topicalizability (and, as will be argued, corresponding lexical semantic properties of preverbs.)
} 
constituent structure behavior: some PVs can appear independent of their verbal stems within a clause, while others cannot. In the present section we will show that this obvious difference obscures some significant similarities. In particular, the presence of a PV whether separable or inseparable - can affect the lexical semantics of the complex predicates, their argument structure, case government and/or function assignments. In addition, the word forms which express some of these complex predicates exhibit parallel behaviors with respect to derivational and inflectional operations. We illustrate some of these shared properties and draw out their theoretical consequences below. ${ }^{9}$

\subsubsection{Lexical Effects}

In this section we demonstrate several ways in which uniform effects on lexical semantics (and correlated argument structures and function assignments) are exhibited by complex predicates independent of the (in)separability of preverbs. We focus here, for the most part, on the unsystematic relations unarguably associated with lexical effects, although regular and semi-regular patterns exist as well. In all instances we demonstrate that (in)separability is irrelevant to the observed behaviors.

First of all, in numerous cases there is no systematic relationship between the meaning of $\mathrm{V}$ and the meaning of PV V. This meaning relation is independent of the (in)separable status of the PV.

$\begin{array}{llll}\begin{array}{l}\text { nehmen } \\ \text { rufen }\end{array} & \begin{array}{l}\text { 'to take' } \\ \text { 'to shout' }\end{array} & \begin{array}{l}\text { an=nehmen } \\ \text { an=rufen }\end{array} & \begin{array}{l}\text { 'to accept' } \\ \text { 'to phone' }\end{array} \\ \begin{array}{l}\text { kaufen } \\ \text { fahren }\end{array} & \text { 'to buy' } & \text { ver-kaufen } & \text { 'to sell' } \\ \text { 'to drive' } & \text { ver-fahren } & \text { 'to lose one's way' }\end{array}$

Secondly, in numerous cases there is no systematic relationship between the valences of $\mathrm{V}$ and PV V:

$\begin{array}{cccc}\begin{array}{c}\text { gehen }(\text { Intr) } \\ \text { contract' }\end{array} & \text { 'go' } & \text { ein=gehen }(\mathrm{Tr}) & \text { 'enter a } \\ \text { treffen }(\mathrm{Tr}) & \text { 'meet' } & \text { ein=treffen }(\text { Intr) } & \text { 'arrive' } \\ \text { dauern (Intr) } & \text { 'last' } & \text { be-dauern }(\mathrm{Tr}) & \text { 'regret' }\end{array}$

\footnotetext{
${ }^{9}$ See Stiebels and Wunderlich (1994) for additional arguments for the lexical nature of these compositions.
} 
Third, in numerous instances there is no systematic relationship between the existence of V and PV V: there are some verbal stems that can serve as a base for certain PVs yielding PV V, some which cannot, and there are some complex predicates (PV V) where $\mathrm{V}$ does not exist independently. These phenomena are exemplified below:

\begin{tabular}{|c|c|c|c|}
\hline fallen & 'fall' & ein=fallen & 'occur' \\
\hline glauben & 'believe' & $*_{\text {ein }=\text { glauben }}$ & - \\
\hline *deutschen & - & ein=deutschen & 'to Germanize' \\
\hline ziehen & 'draw' & er-ziehen & 'raise' \\
\hline glauben & 'believe' & *er-glauben & - \\
\hline *gänzen & - & er-gänzen & 'to complement' \\
\hline
\end{tabular}

As can be seen in the preceding examples, the formation of complex predicates is independent of the (in)separable status of participating PVs.

Fourth, both separable and inseparable PV V combinations undergo function changing rules:

a. Passive:

weil Peter Maria an=ruft. because Peter Maria up-calls

'because Peter calls Maria up.'

(16) weil Maria an=gerufen wurde. because Maria up-called became

'because Maria was called up.'

(17) weil ein Holländer das Teleskop er-funden hat. because a Dutchman the telescope invented has 'because a Dutchman invented the telescope.'

weil das Teleskop von einem Holländer er-funden wurde. because the telescope by a Dutchman invented became 'because the telescope was invented by a Dutchman.'

Finally, both separable and inseparable PV V combinations behave like simplex lexical items in that they can determine the morphological case of their complements. This is shown below: 
Occur with Dative

$\begin{array}{ll}\text { helfen } & \text { 'to help' } \\ \text { bei=stehen } & \text { 'to support' }\end{array}$

be-gegnen 'to meet'
Occur with Accusative

treffen 'to meet'

ein=stellen 'to hire'

be-suchen 'to visit'

\subsubsection{Morphological Effects: Participation in Derivation}

In this section we enumerate several parallel behaviors of complex predicates with respect to derivation independent of the separability of their preverbs. We focus primarily on a comparison between Type 1 and Type 2 compositions, since the behavior of Type 3 compositions resembles these in relevant respects.

First, there is often no systematic relationship between the form of the nominalization of $\mathrm{V}$ and the form of the nominalization of PV $\mathrm{V}$ :

\begin{tabular}{|c|c|c|c|}
\hline $\begin{array}{l}\text { fahren } \\
\text { an=fahren }\end{array}$ & $\begin{array}{l}\text { 'to drive' } \\
\text { 'to hit in a car accident' }\end{array}$ & $\begin{array}{l}\text { Fahrt } \\
\text { *Anfahrt }\end{array}$ & 'ride' \\
\hline $\begin{array}{l}\text { laufen } \\
\text { an=laufen }\end{array}$ & $\begin{array}{l}\text { 'to run' } \\
\text { 'to take off' }\end{array}$ & $\begin{array}{l}\text { Lauf } \\
\text { Anlauf }\end{array}$ & $\begin{array}{l}\text { 'run' } \\
\text { 'take-off run' }\end{array}$ \\
\hline $\begin{array}{l}\text { bringen } \\
\text { an=bringen }\end{array}$ & $\begin{array}{l}\text { 'to bring' } \\
\text { 'to install' }\end{array}$ & $\begin{array}{l}\text { *Bringung } \\
\text { Anbringung }\end{array}$ & '- \\
\hline $\begin{array}{l}\text { raten } \\
\text { be-raten }\end{array}$ & $\begin{array}{l}\text { 'to guess' } \\
\text { 'to advise' }\end{array}$ & $\begin{array}{l}\text { Rat } \\
* \text { Berat }\end{array}$ & 'advice' \\
\hline $\begin{array}{l}\text { greifen } \\
\text { be-greifen }\end{array}$ & $\begin{array}{l}\text { 'to grasp at' } \\
\text { 'to understand' }\end{array}$ & $\begin{array}{l}\text { Griff } \\
\text { Begriff }\end{array}$ & $\begin{array}{l}\text { 'grip' } \\
\text { 'notion' }\end{array}$ \\
\hline $\begin{array}{l}\text { dürfen } \\
\text { be-dürfen }\end{array}$ & $\begin{array}{l}\text { 'to be allowed' } \\
\text { 'to need' }\end{array}$ & Bedarf ${ }^{* \text { Darf }}$ & 'need' \\
\hline
\end{tabular}

Second, both separable and inseparable PV V combinations can undergo lexical derivations which the stem alone cannot undergo: 


$\begin{array}{lll}*[[\text { deutsch }] \text { en }] & {[[\text { ein=deutsch }] \text { en }]} & \text { 'to Germanize' } \\ *[[\text { deutsch }] \text { ung }] & {[[\text { Ein=deutsch }] \text { ung }]} & \text { 'Germanization' } \\ *[[\text { frisch }] \text { en }] & [\text { [er-frisch }] \text { en }] & \text { 'to refresh' } \\ *[[\text { frisch }] \text { ung }] & {[[\text { Er-frisch }] \text { ung }]} & \text { 'refreshment' }\end{array}$

Finally, another example of the ability of the complex predicate to undergo derivational operations concerns the regular formation of adjectives from verbs using the suffix -bar: this operation is, once again, independent of the (in)separable status of the PV:

(22a) weil wir die Informationen jederzeit $\underline{a b=r u f e n ~ k o ̈ n n e n . ~}$

because we the information always call-up can

'because we can obtain the information at any time.'

(22b) weil die Informationen jederzeit ab=ruf-bar sind.

because the information always up-call-able are

'because the information is obtainable at any time.'

(23a) weil wir die Mieten hier noch be-zahlen können.

because we the rents here still pay can

'because we can still afford the rent here.'

(23b) weil die Mieten hier noch be-zahl-bar sind.

because the rents here still pay-able are

'because the rent is still affordable here.'

\subsubsection{Summary}

The preceding discussion has demonstrated that there are certain clear similarities between different types of German complex predicates consisting of a PV and V: these similarities are independent of the surface expression of these entities, since they are maintained irrespective of the (in)separability of the PV and V. For our purposes, we will assume that these similarities argue for the assumption that all three types are associated with lexical representations. For the moment it is important to note why these constructions are important for the present analysis. We have established the existence of a class of complex predicates which consist of syntactically separable pieces and yet are associated with lexical representations: the fact that there are entities which display uniformities with respect to certain sorts of information, but differ considerably with respect to other sorts of information is precisely the type of discrepancy which lends support to the postulation of distinct levels in correspondence with one another. In 
particular, the PV V combinations reviewed above all share certain argument structure properties, exhibit a morphological status, but differ with respect to their syntactic behaviors. It is now time to turn to other examples of the independence of phrasal expression from lexical representation.

\section{Topicalization and Complex Predicates}

In this section we review the patterns of topicalizability associated with several different types of verbal constructions. We begin with a discussion of the $\mathrm{PV}+\mathrm{V}$ compositions, since these exhibit the greatest assortment of standard lexical effects. These entities also possess a morphological status as indicated in the previous section. We continue our examination by focusing on a class of predicates which evince some lexical effects, namely, passive and causative predicates which exhibit grammatical function changes and/or alterations of argument structure. Finally we review constructions which present neither direct morphological nor standard lexical evidence for being interpreted as associated with lexical representations: they serve neither as bases for morphological operations nor do they exhibit grammatical function changes. We suggest, however, that even these constructions warrant inclusion in the class of complex predicates. For purposes of exposition across classes of predicates the following conventions will be used: $\mathrm{X}=$ the left member, $\mathrm{Y}=$ the right member, $\mathrm{X}+\mathrm{Y}=$ the entire composition.

\subsection{Complex Predicates I}

In this section we examine the behaviors of $\mathrm{PV}+\mathrm{V}$ compositions with respect to topicalization. For purposes of exposition we decompose the predicates in the following way:

Prefix $+\mathrm{V}$, Type 1

Prefix $+V$, Type 2

Prefix $+V$, Type 3

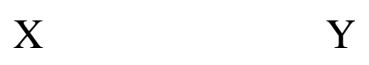

$\begin{array}{ll}\text { er- } & \text { ziehen } \\ \text { an }= & \text { rufen } \\ \text { auf }= & \text { machen }\end{array}$

The division of the predicates into two pieces permits us to ask three basic questions concerning the interaction between these predicates and topicalization: (i) Can parts $\mathrm{X}$ 
and $\mathrm{Y}$ be topicalized together?, (ii) Can part $\mathrm{X}$ be topicalized without part $\mathrm{Y}$ ?, and (iii) can part $\mathrm{Y}$ be topicalized without part $\mathrm{X}$ ?

\subsection{Topicalization and Complex Predicates I}

As illustrated below the entity defined as $\mathrm{X}+\mathrm{Y}$ can be topicalized as a whole:

(25a) [Er-zogen] hat sie das Kind t.

up-brought has she the child

'She brought the child up.'

(25b) [An=gerufen] hat er die Frau t. up-called has he the woman

'He called the woman up.'

(25c) $\quad[$ Auf=gemacht $]$ hat er das Fenster t. open-made has he the window

'He opened the window.'

There are differences with respect to the topicalizability of $\mathrm{X}$ in these three constructions. In fact, this distributional difference is one of the properties which warrant distinguishing between Type 2 and Type 3 PV V constructions: whereas PVs in Type 2 constructions cannot topicalize (26b), PVs in Type 3 constructions can (26c).

$(26 a) *[\mathrm{Er}]$ hat sie das Kind t zogen.

up has she the child brought

'She brought up the child.'

$(26 \mathrm{~b}) *$ [An] hat er die Frau $t$ gerufen.

up has he the woman called

'He called the woman up.'

(26c) [Auf] hat er das Fenster $t$ gemacht. open has he the window made 'He opened the window.'

All of the PV V constructions behave alike in that part Y cannot be topicalized.

$(27 a) *[$ Zogen $]$ hat sie das Kind er t. brought has she the child up

'She brought the child up.' 
(27b) * [Gerufen] hat er die Frau an t. called has he the woman up

'He called the woman up.'

$(27 \mathrm{c}) *$ [Gemacht $]$ hat er das Fenster auf t. made has he the window open

'He opened the window.'

\subsection{Complex Predicates II: Function Changing Operations}

In the previous subsection we observed the distributional behaviors of compositions which display lexical effects standardly associated with synthetically expressed word forms. In the present subsection we extend the investigation to analytically expressed compositions which evince some key properties associated with lexical operations among lexicalists, namely, meaning changes, valence changes and function changes. These constructions are passive, which display function reassignments relative to related active forms, and causative, where there are meaning changes, valence changes, and function changes relative to the base predicate on which the causative is formed. These constructions are illustrated below, where the italicized element is an analog of the PV and the boldfaced element is an analog of the verbal stem.

Passives:

(28a) weil der Mann die Blumen [geschenkt bekam].

because the man the flowers given got

'because the man was given the flowers.'

Causatives:

(28b) weil Peter den Wagen von dem Jungen [waschen ließ]. because Peter-NOM the car-ACC by the boy wash let 'because Peter had the car washed by the boy.'

The pieces of these predicates can be divided as follows:

Types of Predicates: 


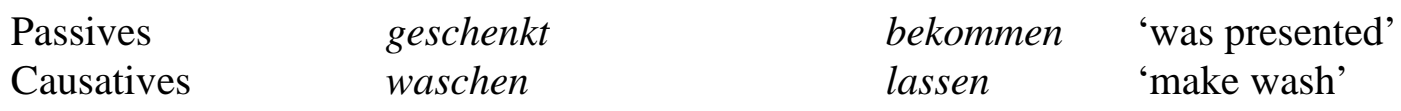

\section{Questions about Distribution}

As can be seen, the entity defined as $\mathrm{X}+\mathrm{Y}$ can be topicalized as a whole unit:

(30a) [Geschenkt bekommen] hat der Mann die Blumen t. given got has the man the flowers-Acc

'The man has been given the flowers.'

(30b) [Waschen lassen] hat Hans den Wagen von dem Jungen t. wash let has Hans the car-ACC by the boy

'Hans has let the car be washed by the boy.'

The $\mathrm{X}$ element of the composition can be topicalized alone:

(31a) [Geschenkt] hat der Mann die Blumen t bekommen. given has the man the flowers-ACC gotten

'The man has been given the flowers.'

(31b) [Waschen] hat Hans den Wagen von dem Jungen t lassen. wash has Hans the car-ACC by the boy let

'Hans has let the car be washed by the boy.'

The Y element cannot be topicalized alone:

(32a) * [Bekommen] hat der Mann die Blumen geschenkt t. gotten has the man the flowers-ACC given

'The man has been given the flowers.'

$(32 \mathrm{~b}) *$ [Lassen] hat Hans den Wagen von dem Jungen waschen t. let has Hans the car-ACC by the boy wash

'Hans has let the car be washed by the boy.'

\subsection{Complex Predicates III}

The next constructions we examine differ from the previous constructions in that they do not exhibit any standard lexical effects, e.g. PREDICATE nominals/adjectives and constructions containing modal and aspectual "auxiliaries:"

weil Hans ein Busfahrer gewesen ist.

because Hans a bus driver been is

'because Hans was a bus driver.' 
weil Hans krank gewesen ist.

because Hans sick been is

'because Hans was sick.'

(35) weil Hans singen können wollte.

because Hans sing can wanted

'because Hans wanted to be able to sing.'

The formal expression of these three types of constructions can be analyzed in the same manner as was done for the previous types of constructions.

Types of Predicates:

\begin{tabular}{llll}
\multicolumn{1}{c}{$\mathrm{X}$} & $\mathrm{Y}$ & \\
Predicate Nominal & ein Busfahrer & sein & 'be a bus driver' \\
$\begin{array}{l}\text { Predicate Adjective } \\
\text { krank } \\
\text { Modal }\end{array}$ & $\begin{array}{l}\text { seingen } \\
\text { können }\end{array}$ & 'be sick' 'be able to sing'
\end{tabular}

Questions about Distribution

The entity defined as $\mathrm{X}+\mathrm{Y}$ can be topicalized as a unit:

NP + Copula:

(36a) [Ein Busfahrer gewesen] ist Hans t.

a bus driver been is Hans

'Hans was a bus driver.'

$\underline{\text { AP + Copula: }}$

(36b) [Krank gewesen] ist Hans t.

sick been is Hans

'Hans was sick.'

$\underline{\mathrm{V}+\text { Auxiliary: }}$

(36c) [Singen können] wollte Hans t.

sing can wanted Hans

'Hans wanted to be able to sing.'

The element characterized as X can be topicalized alone: 
$\underline{\text { NP + Copula: }}$

(37a) [Ein Busfahrer] ist Hans t gewesen.

a bus driver is Hans been

'Hans was a bus driver.'

$\underline{\text { AP + Copula: }}$

(37b) [Krank] ist Hans t gewesen.

sick is Hans been

'Hans was sick.'

$\underline{\mathrm{V}+\text { Auxiliary: }}$

(37c) [Singen] wollte Hans t können.

sing wanted Hans can

'Hans wanted to be able to sing.'

The Y element cannot be topicalized alone:

NP + Copula:

(38a) * [Gewesen] ist Hans ein Busfahrer t. been is Hans a bus driver

'Hans was a bus driver.'

$\underline{\text { AP + Copula: }}$

(38b) * [Gewesen] ist Hans krank t. been is Hans sick

'Hans was sick.'

$\underline{\mathrm{V}+\text { Aux: }}$

(38c) * [Können] wollte Hans singen t. can wanted Hans sing

'Hans wanted to be able to sing.'

\subsection{Idiomatic vs. Non-idiomatic VPs}

German has idiomatic expressions consisting of a verb and one or more of its syntactic arguments. We provide two examples of such idioms. In the first example below the verb forms an idiom with its NP object, while the second one exemplifies an idiom with a PP complement. 
(39) weil Hans den Vogel abgeschossen hat. because Hans the bird shot-off has 'because Hans stole the show.'

(40) weil er ins Gras gebissen hat. because he into-the grass bitten has

'because he died.'

In this section we compare idiomatic VPs with structurally identical non-idiomatic VPs of the following type:

$$
\begin{aligned}
& \text { (41) weil er den Apfel gegessen hat. } \\
& \text { because he the apple eaten has } \\
& \text { 'because he ate the apple.' } \\
& \text { (42) weil er in den Apfel gebissen hat. } \\
& \text { because he into the apple bitten has } \\
& \text { 'because he bit into the apple.' }
\end{aligned}
$$

Following the format employed throughout this paper the VPs can be represented schematically as follows:

\section{X}

Idiomatic VP den Vogel

Non-idiomatic VP den Apfel
Y

abschießen 'shoot the bird" 10 essen 'eat the apple'

Note that $\mathrm{X}+\mathrm{Y}$ (i.e. the VP) can topicalize: ${ }^{11}$

\footnotetext{
${ }^{10}$ This expression means 'to show off, steal the show'. Whereas we have focused attention here on semantically opaque idioms it is frequently observed that languages exhibit a large spectrum of idiomatic expressions with varying degrees of semantic transparency. Further research is needed in order to determine whether semantic differences reliably correspond to syntactic behavioral differences.
} 


\section{Idiomatic VP:}

(44) [Den Vogel abgeschossen] hat Hans t. the bird shot-off has Hans

'Hans stole the show.'

(45) [Ins Gras gebissen] hat er t. into-the grass bitten has he 'He died.'

\section{Non-idiomatic VP:}

(46) [Den Apfel gegessen] hat er t. the apple eaten has he

'He ate the apple.'

(47) [In den Apfel gebissen] hat er t. into the apple bitten has he 'He bit into the apple.'

The element $\mathrm{X}$ can topicalize without $\mathrm{Y}$ :

\section{Idiomatic VPs:}

(48) [Den Vogel] hat Hans t abgeschossen. the bird has Hans shot-off

'Hans stole the show.'

(49) [Ins Gras] hat er t gebissen. into-the grass has he bitten 'He died.'

\section{Non-idiomatic VPs:}

(50) [Den Apfel] hat er t gegessen. the apple has he eaten

'He ate the apple.'

\footnotetext{
${ }^{11}$ Felicitously topicalizing the whole VP in this manner requires very specific discourse conditions which we will not attempt to specify here. We forego discussing topicalizations of VPs as well as remnants of VPs here.
} 
(51) [In den Apfel] hat er t gebissen.

into the apple has he bitten

'He bit into the apple.'

Finally, whereas $\mathrm{Y}$ can topicalize without $\mathrm{X}$ in non-idiomatic VPs, it cannot topicalize in idiomatic VPs (the non-idiomatic readings are available, however):

\title{
Non-idiomatic VPs:
}

(52) [Gegessen] hat er den Apfel t. eaten has he the apple

'He ate the apple.'

(53) [Gebissen] hat er in den Apfel t. bitten has he into the apple

'He bit into the apple.'

$\underline{\text { Idiomatic VPs: }}$

(54) * [Abgeschossen] hat Hans den Vogel t. shot-off has Hans the bird

'Hans stole the show.'

(55) * [Gebissen] hat er ins Gras t. bitten has he into-the grass

'He died.'

\subsection{Summary of the Evidence from Topicalization}

The table below contains the grammaticality judgments of the thirty cases we have examined in section 2.3: "ok" = topicalizable, "*” = not topicalizable.

\author{
Topicalizability
}

$\mathrm{X} \quad \mathrm{Y} \quad \mathrm{X}+\mathrm{Y}$

(i) er-ziehen

$* \quad *$

ok 
(ii) $\quad$ an=rufen

(iii) $a u f=$ machen

(iv) geschenkt bekommen

(v) waschen lassen

(vi) ein Busfahrer sein

(vii) kranksein

(viii) singen können

(ix) den Vogel abschießen

(x) den Apfel essen

$\begin{array}{ll}* & * \\ \text { ok } & * \\ \text { ok } & * \\ \text { ok } & * \\ \text { ok } & * \\ \text { ok } & * \\ \text { ok } & * \\ \text { ok } & \text { ok } \\ \text { ok } & \end{array}$

ok ok ok

ok

ok

ok

ok

ok

ok

ok

ok

There are several clear patterns in this table: (i) all ten collocations can be topicalized as a whole, (ii) the PV+V combinations of Types 1 and 2 do not allow their first constituent to topicalize alone, and (iii) all constructions except non-idiomatic VPs disallow their second constituent from topicalizing alone.

The following behaviors are also worth noting:

(1) Types 1 and $2 \mathrm{PV}+\mathrm{V}$ combinations behave alike as exhibited by (56i) and (56ii). They behave differently from Type 3 as exhibited by (56ii) and (56iii). This suggests that separability per se cannot be an explanation for the observed constraints.

(2) Type $3 \mathrm{PV}+\mathrm{V}$ combinations e.g. (56iii) behave like constructions containing auxiliaries e.g. (56iv, v, vi, vii, viii).

In addition, there are two other sorts of similarities which are significant but which are not apparent in the table:

(58)

(1) All analytically expressed predicates bear neutral prominent stress on the X or leftmost element of the composition.

(2) The categorial V in all analytically expressed predicates participates in V2, while the other piece of the complex predicate cannot appear with it in second position.

These points of local comparison indicate that neither separability nor categoriality appear to be explanatory for the distributions at hand. In addition there are certain global similarities which any analysis must address: (i) what unifies the topicalizability of all the elements which can topicalize? and (ii) what prohibits all of the 
elements which cannot topicalize from topicalizing? In summary, despite obvious local differences between these compositions there are certain identifiable similarities.

In the earlier discussion of Functional Uncertainty it was suggested that the value of the TOPIC function is identified with some value for a standard grammatical function such as SUBJ, OBJ etc. The table above shows, however, that certain elements can be topicalized for which the standard inventory of grammatical functions contains no appropriate function value. An example appears below:

weil er [in den Apfel gebissen] hat. because he into the apple bitten has

'He bit into the apple.'

Standard LFG would associate the XCOMP function with the VP in den Apfel gebissen. ${ }^{12}$ Accordingly, standard FU would permit the topicalization of the entire VP. The VP as a maximal category would be associable with the XCOMP function: the VP could be a TOPIC and could serve as the value for the XCOMP function associated with the matrix verb hat 'has' interpreted as a raising predicate. On the other hand, as entry ( $\mathrm{x}$ ) in table (56) shows, the head of the presumptive XCOMP can topicalize alone. That is, if the matrix categorial verb is interpreted, as in standard analyses, as heading its own clause nucleus and selecting for an XCOMP function, the full distribution of topicalization cannot be accounted for. A complementary problem obviously arises with respect to such idiomatic VPs as that exemplified in (ix): as predicted on the standard FU account, the entire VP is topicalized and provides a value for the ostensible XCOMP function associated with the matrix verb. Clearly the problem is not that such constructions behave as they do, since this behavior is predicted by FU. Rather, the problem is that this behavior is restricted to idiomatic VPs and that this seems accidental on the FU account.

In summary, non-idiomatic VPs behave anomalously with respect to the predictions of standard FU, while idiomatic VPs behave as predicted. Why should there be any difference at all in the behaviors of these two types of VPs and why should each type behave precisely as it does? These are questions we will address below.

\footnotetext{
${ }^{12}$ An XCOMP in LFG is a dependent predicating complement whose SUBJ function is not overtly expressed and receives its value from a function in another clause. A standard instance of this phenomenon is in socalled raising constructions such as 'Mary seems to be singing', the XCOMP is 'seems to be singing' and the value for its unexpressed SUBJ is the SUBJ complement of 'seems'.
} 
A second type of example for which an appropriate grammatical function assignment would be problematic is seen in sentences which involve the topicalization of a verb cluster such as those represented in entries (56 iv, v, viii):

[Geschenkt bekommen] hat Hans das Buch. given got has Hans the book

'Hans was given the book.'

(61) [Schenken lassen] hat Hans dem Jungen das Buch. give let has Hans the boy the book

'Hans had the book given to the boy.'

The question arises as to whether there are any plausible function assignments which could be given to the topicalizable elements. This issue will be explored in the following section. ${ }^{13}$

A third type of problem for standard FU arises when we consider di-transitive VPs. Here the verb can be topicalized by itself and any combination of verb plus internal arguments can as well.

(62) [Geschenkt] hat Hans dem Jungen das Buch. given has Hans-NOM the boy-DAT the book-ACC 'Hans gave the boy the book.'
[Das Buch geschenkt] hat Hans dem Jungen. the book-ACC given has Hans-NOM the boy-DAT 'Hans gave the boy the book.'

[Dem Jungen geschenkt] hat Hans das Buch. the boy-DAT given has Hans-NOM the book-ACC 'Hans gave the boy the book.'
[Dem Jungen das Buch geschenkt] hat Hans. the boy-DAT the book-ACC given has Hans-NOM 'Hans gave the boy the book.'

\footnotetext{
${ }^{13}$ For considerations of space we will ignore in the following discussion a recent and relevant proposal for the treatment of Russian analytic tense and yes/no question constructions within a version of LFG constituent-structure that assumes multiple constituent-structure heads, rather than the relation between a matrix predicate and an embedded XCOMP discussed above. (See Holloway-King 1995 for discussion.)
} 
The topicalized constituent in the first three examples does not bear a grammatical function from the standard function set. We will not address these distributions in this paper. $^{14}$

\section{The Lexical Representation of Complex Predicates: Functional Predicates}

In this section we argue that the usual inventory of grammatical functions should be augmented to include a PREDICATE function. This assumption yields the following interpretation for the summary of distributions cited in (56) above:

\section{Summary of Distributions (Attributions of Function)}

(i) er-ziehen

(ii) an=rufen

(iii) auf=machen

(iv) geschenkt bekommen

$\mathrm{X}$

$*$

$*$

PRED

PRED

PRED

PRED

PRED

PRED

OBJ

OBJ

\section{Y}

$\mathrm{X}+\mathrm{Y}$

PRED

PRED

PRED

PRED

PRED

PRED

PRED

PRED

PRED

PRED

\footnotetext{
${ }^{14}$ We will forego discussion in this article of VP topicalization in its various forms, since we are focusing on lexical constructions. A question that we leave untouched here is the nature of the phrasal projections in these sentences, since this requires answers to such vexing and controversial questions as whether German has a VP, whether verb clusters are dominated by $\mathrm{X}^{\mathrm{O}}$ categories, etc. On contrary views with respect to the former, see Haider (1981, 1985), den Besten (1985), and Webelhuth (1992). Verb clusters are discussed and analyzed differently in Evers (1975), Haegeman and van Riemsdijk (1986) and Bierwisch (1990), among many others.

While there may be disagreement about the nature of German constituency, most linguists who have worked on this issue would support the view that all the strings preceding the finite verb in (62) - (65) form one constituent headed by a verb which in our theory would be part of a functional word. No more specific assumptions are necessary for our approach to be empirically successful.
} 
In the remainder of this paper we motivate this function assignment by addressing the following two questions: (i) what is the PREDICATE function? and (ii) what can bear this function?

Let us assume that the PREDICATE function is a primitive borne by the head of a clause. This assumption has played an explanatory role in the analysis of several different phenomena within Relational Grammar since Perlmutter (1979) as well as in the theory developed in Ackerman and Webelhuth (1998). ${ }^{15}$ In ordinary circumstances the head of a clause is a single verbal element such as the simple verb essen 'to eat' in (66x) or the complex verb er-ziehen 'to raise' in (66i). That is, the PREDICATE function is associated with a synthetic morphological object. On the other hand, we have argued that complex predicates such as those represented in (66ii) and (66iii) differ from predicates like those in (66i) only with respect to the separability of their pieces. Whereas the latter is encoded synthetically in accord with the usual expectations of the so-called Lexical Integrity Hypothesis, the former are somewhat anomalous in that they are expressed analytically. Given this, let us assume that the PREDICATE function is not associated with any specific type of morphological object (namely, synthetic or analytic), but rather with the lexical representation of such entities. That is, the PREDICATE function is associated with lexical representations independently of the surface expression of these entities. We have seen that this is an independently motivated assumption for the analysis of Hindi complex predicates. This proposal conforms with a tradition in linguistics according to which the notion word is multifaceted. ${ }^{16}$ As observed in Matthews (1974), Zwicky (1990) and Anderson (1992), among others, the object denoted by the notion word has a phonological, morphological and syntactic status: these different aspects of wordhood sometimes exhibit mismatches. With T. Mohanan we propose that there is another, somewhat overlooked but nonetheless significant, aspect of wordhood. We will refer to this as functional or lexical wordhood. ${ }^{17}$ We will assume that the Strong Lexicalist Hypothesis restricts the manipulation of certain types of information solely to lexical representations: a lexical entry will thus necessarily contain, among other things,

\footnotetext{
${ }^{15}$ This construct is a central explanatory notion in the proposals of Davies and Rosen (1988), and C. Rosen (1988).

${ }^{16}$ This view has been revitalized in various recent analyses (cf. Sadock (1991), Grimshaw (1982), Bresnan and Kanerva (1989), Inkelas (1989), Di Sciullo \& Williams (1987) etc.). In earlier work the necessity for distinguishing between different dimensions of wordhood can be found in Lehiste (1964), Matthews (1972), Dixon (1976), Zirmunskij and Sunik (1963), among others.

${ }^{17}$ Cf. Ackerman $(1984,1987)$ and T. Mohanan (1990/1994).
} 
information concerning lexical semantics (and the related mapping between arguments and functions) and morphosyntactic information (agreement, aspect, tense, modality etc.). This is the type of information contained in LFG lexical forms, certain aspects of which define a clause nucleus in LFG, as mentioned previously.

Adoption of the Strong Lexicalist Hypothesis and LFG's PRINCIPLE OF DIRECT SYNTACTIC ENCODING, whereby only lexical rules can effect grammatical function assignments, yields the following conclusion with respect to (complex) predicate formation: the lexical rules that relate lexical representations are responsible for (complex) predicate formation. Inasmuch as some of the complex predicates investigated here are made up of syntactically separable pieces, we are proposing that there is something amiss in the usual assumption that the output of lexical rules yields a single morphological item displaying lexical integrity. Predicate formation operations, then, do not conform to what might be called the Hypothesis of Morphological Lexicalism:

Hypothesis of Morphological Lexicalism

All predicate forming operations, whether conceived syntactically in terms of head-movement (i.e. Baker (1988) or lexically ( i.e. Di Sciullo and Williams (1987) or Bresnan (1982)), yield morphological objects, i.e. morpho-phonologically integrated word forms.

The necessity of abandoning the Hypothesis of Morphological Lexicalism in order to account for all three types of $\mathrm{PV}+\mathrm{V}$ combinations leaves open the possibility that there are other lexical representations which would fall within the constraints established by the PRINCIPLE OF DIRECT SYNTACTIC ENCODING ${ }^{18}$. The PREDICATE function can consequently be associated with entities which exhibit grammatical function changes such as those in (66iv) and (66v). Since being the expression by a single morphological object is not a necessary condition for being associated with a lexical representation or being a functional word, it is similarly possible to assume that entities which do not exhibit function changes such as those in (66vi, vii, viii) bear the PREDICATE function. These latter compositions display the types of modulation in meaning associated with inflectional morphology and given the Strong Lexicalist Hypothesis are expected to be associated with this information in their lexical representations. That is, having distinguished between what one might refer to as the lexemic and the morphosyntactic information associated with lexical representations and their formal expression, we can maintain such principles as the Strong Lexicalist Hypothesis and Direct Syntactic

\footnotetext{
${ }^{18}$ For further discussion of this issue see Bresnan and Mchombo (1995) and Ackerman and Lesourd (1997).
} 
Encoding but only insofar as they have scope over functional or lexical words rather than morphological objects.

Since idioms are generally regarded to have lexical representations as units independent of their internal constituency - they can likewise be associated with the PREDICATE function. Despite the similarity of their behaviors the constructions in (66i viii) clearly differ in status from idioms: whereas the former are all interpretable as complex predicates, the latter generally is not. On the other hand, what these different constructions share is that they all have lexical representations. The basic generalization that relates them therefore seems to be this: lexical representations are associated with the PREDICATE function independent of the morphological and syntactic status of the manner in which they receive surface expression. This generalization extends to explain the PREDICATE function attribution to the $\mathrm{X}+\mathrm{Y}$ combinations in (66i - ix) and to the $\mathrm{Y}$ element in (66x). However, we can see from the table that certain phrasal units such as the nonidiomatic VP in (66x) bear the PREDICATE function. This indicates that certain phrasal entities without apparently defensible lexical representations can bear the PREDICATE function. In addition, it appears that certain pieces of complex predicates can themselves bear the PREDICATE function as indicated in (66iii - viii). We will first examine the pieces of complex predicates and then turn to phrasal expressions.

\section{The Pieces of Complex Predicates}

Throughout we have decomposed German complex predicates into two pieces, namely, $\mathrm{X}$ and $\mathrm{Y}$. We have seen that certain $\mathrm{X}$ elements bear the PREDICATE function, while others do not. The Y element only bears this function in non-idiomatic VPs. In the present section we will seek an explanation for these distributions in terms of the disjoint expression of information associated with pieces of these predicates. In particular, we will suggest that for constructions (66iii - viii) the $\mathrm{X}$ element is interpretable as the semantically dominant element, referred to here as $\mathrm{C}$ (ore), while the $\mathrm{Y}$ element, referred to here as the $\mathrm{H}(\mathrm{ead})$, is semantically subordinate. ${ }^{19}$ The notion of semantic dominance can be interpreted as follows:

(68) Semantic Dominance

\footnotetext{
19 These notions of CORE and HEAD are further developed in Ackerman and Webelhuth (1998). See Andrews and Manning (1993/In press) for a different use of notions such as C and H within a revised version of LFG, but one which tries to capture some of the same monoclausal effects for complex predicates as those addressed here.
} 
If $\alpha$ semantically selects $\beta$ in the complex predicate [ $\beta \alpha$ ], then $\beta$ semantically dominates $\alpha$.

In other words, an $\mathrm{H}(\mathrm{ead})$, corresponding to $\alpha$, serves as a defective predicate which combines with another element of determinate categoriality, corresponding to the semantically dominant entity $\beta$, in order to create a complete complex predicate. ${ }^{20}$ The composition process yields a lexical representation construable as a lexical word. For German, we can say that:

(69) The PREDICATE function is associated with the $\mathrm{C}$ of a semantically compositional lexical word and with the lexical word as a whole. It is never associated with the $\mathrm{H}$ of a lexical word alone.

We will also assume the following revised schema for Functional Uncertainty:

\section{Final Revised Schema for Functional Uncertainty}

$$
\begin{array}{ccc}
\mathrm{S}^{\prime}---> & \Omega & \Sigma \\
& (\uparrow \mathrm{DF}=\downarrow) \\
& (\uparrow \mathrm{DF})=(\downarrow \text { BODY* BOTTOM })
\end{array}
$$

Where $\mathrm{DF}=$ discourse function, the values for Body and Bottom is some (set of) $\mathrm{GF}(\mathrm{s})$, inclusive of the PREDICATE, and $\bullet=\mathrm{XP}$ or $\mathrm{X}$, and $\Sigma=\mathrm{S}$.

\section{Figure 13}

As mentioned previously, both the need to posit a PREDICATE function and the assumption that non-maximal categories can bear grammatical functions derive independent motivation within LFG. For German, we assume that the relevant inventory of traceable functions includes the PREDICATE, and that German is a language where nonmaximal categories are associable with grammatical functions. With these assumptions

\footnotetext{
${ }^{20}$ Hypotheses along these lines have been argued for independently in Ackerman and Webelhuth (1993), Webelhuth (1994), and Alsina (1993). A view of this sort also recalls the basic insight concerning so-called "light" and "semi-light" predicates in Grimshaw and Mester (1988) and S. Rosen (1989) among others. Finally, it should be evident that the proposed general characterization of semantic dependence for operators appropriately leaves open the issue as to whether operators are morphologically bound or syntactically independent entities in particular instances.
} 
we can account for the classes of complex predicates and the behavioral paradigms reviewed above.

\subsection{Type 1 and Type 2 PV + V Compositions}

The composition of PV and V stems exemplified by inseparable PVs (as in 66i) and separable PVs (as in 66ii), results from a derivational process which combines the pieces to produce a complex predicate. Neither of the pieces of this assemblage bear a grammatical function, while the entire composition bears the PREDICATE function. However systematic or unsystematic such combinations may be, they simply yield complex lexical representations with a morphological status. That is, the relevant compositions represent the unmarked case of complex word forms in that they do not allow their pieces to be functionally identified. That they are alike despite differences concerning separability is evident from the fact that they can both serve as input to various morphological operations. For example, recall that both serve as bases for adjective formation with the suffix -bar.

\section{(70)}

PV inseparable: er-zieh+bar $\mathrm{PV}_{\text {separable: }} a b=z i e h+b a r$

Indeed, it is their morphological status that they share with Type $3 \mathrm{PV}$ V combinations which behave quite differently with respect to topicalization. In particular, the pieces of these compositions together represent the coalescence of $\mathrm{C}$ and $\mathrm{H}$ and this lexical unit is associated with the PREDICATE function: these entities represent a single lexical word despite exhibiting differences with respect to their syntactic behaviors. Crucially, the separable particles of this class do not function as predicates. Given that we are dealing with a single PREDICATE function, it is predicted that the whole complex predicate is topicalizable, while the parts are not - even if these parts are otherwise syntactically independent. In effect, we are claiming that the internal pieces of such compositions are not relevant with respect to grammatical functions.

\subsection{Type 3 PV + V Compositions: Resultatives in German}

The Type 3 separable PV and V stem compositions (as in 66iii) are an instance of complex predicates whose pieces are functionally relevant, i.e. the PV bears the 
PREDICATE function. This distinguishes Type 3 compositions from, e.g. Type 2 compositions, which they otherwise resemble with respect to (i) serviceability as a base for morphological operations, (ii) the location of stress on the PV and (iii) inability of the entire PV + V to satisfy the V2 constraint of German. Type 3 forms are clearly marked with respect to types 1 and 2 in our view. We argue that the difference in topicalizability evident between Type 2 and Type 3 constructions follows from the fact that Type 3 constructions are one sort of surface expression for resultative constructions in German ${ }^{21}$.

Our proposal is this. The verbal head in Type 3 constructions does not bear the lexical meaning it would carry as an independent predicate: it functions as a $\mathrm{H}$ or semantically dependent entity. It also contributes an argument structure to the composed predicate. In contrast, the ostensible secondary predicate, i.e. the $\mathrm{PV}$, functions as the semantic head of such compositions: it serves as $\mathrm{C}$ and consequently bears the PREDICATE function. Of course, the entire lexical word can bear the PREDICATE function since it is the composition of $\mathrm{C}$ and $\mathrm{H}$. In the relevant sense they meet T. Mohanan's characterization of complex predicates:

A COMPLEX PREDICATE construction is one in which two semantically predicative elements jointly determine the structure of a single syntactic clause. (T. Mohanan (1990/1994))

We propose that these resultative constructions are analytically expressed functional words whose semantics accord with the characterization of the English resultative constructions formulated in Goldberg (1995), Levin and Rappaport (1994), and Dowty (1979), Spencer and Zaretskaya 1998, among others.

\section{$\lambda \mathrm{x} \lambda \mathrm{y} \lambda \mathrm{R} \lambda \mathrm{P}((\mathrm{x}$ CAUSE BECOME R (y)) BY P (x y)}

According to this formulation the presumable secondary predicate functions as the semantic head, while the presumable primary predicate assumes an auxiliary adjunct function (and can serve as a categorial head for the composition). In what follows the element contributing the result property $\mathrm{R}$, i.e. the $\mathrm{C}$ entity on our analysis, will be shown to topicalize, while the $\mathrm{H}$ element will be argued to contribute the semantic primitives CAUSE BECOME and an attendant argument structure as well as sometimes contributing additional adverbial semantics, i.e. the property associated with $\mathrm{P}$ above.

\footnotetext{
${ }^{21}$ These complexes are also interpreted as reflexes of resultative constructions in Kratzer (1995).
} 
We begin by discussing Type 3 PV V compositions such as auf=machen 'make open'. We show that the PV in these compositions is syntactically and semantically active, while the verbal stem is inert with respect to topicalizability - recall, however, that it is active with respect to v2. This discussion is followed by some examples of resultative constructions whose categorial profile differs from the Type 3 compositions: the "secondary" predicate in these other resultative constructions is expressed by major categories instead of PVs. We demonstrate that despite their categorial differences all resultative constructions behave identically with respect to topicalization and the verb second constraint. ${ }^{22}$

It might be thought that topicalizability is a property intrinsic to certain PVs. That this assumption is insufficient is illustrated in the following way. There are pairs of complex predicates consisting of identical PVs which exhibit different behaviors with respect to topicalizability. The complex predicates in (72), (73) and (74) all contain separable tokens of the PV auf 'open':

(72) weil er die Tür auf=macht. because he the door open-makes 'because he opens the door.'

(73) weil er die Tür auf=tritt. because he the door open-kicks 'because he kicks the door open.'

(74) weil er das Gold auf=kauft. because he the gold up-buys 'because he buys up the gold.'

Note that auf can only be topicalized in (72) and (73):

(72') [Auf] hat er die Tür gemacht. open has he the door made 'He opened the door.'

\footnotetext{
${ }^{22}$ We also note in passing that though all of the constructions examined here are interpretable as resultative complex predicates, their different categorial make-up explains their differential behavior with respect to participation in morphological operations: whereas resultatives containing a PV can serve as input to derivational operations, resultatives containing major categories cannot. Once again, this would seem to offer evidence for the necessity of being able to distinguish the functional vs. categorial aspects of complex predicates.
} 
(73') [Auf] hat er die Tür getreten.

open has he the door kicked

'He kicked the door open.'

$\left(74^{\prime}\right) *$ [Auf] hat er das Gold gekauft. up has he the gold bought

'He bought up the gold.'

Since the difference in behavior obviously cannot be attributed to the PV itself, it must be attributed to the different functional status played by the PV within the different predicates.

The PVs in (72) and (73) serve as $\mathrm{C}$ and bear the PREDICATE function. From the perspective of the semantic profile of resultatives observed above we can render examples (72) and (73) informally as follows:

(75) (he CAUSE BECOME open (the door) BY DOING SOMETHING (he, the door)

(76) (he CAUSE BECOME open (the door)) BY KICKING (he, the door))

The only difference between (75) and (76) is whether the subordinate element, i.e. the verb, specifies the nature of adverbial modification or not.

On our assumption the difference in topicalizability between auf in (72) and (73) on the one hand and in (74) on the other shows that auf bears the PREDICATE function only in the former sentences. Independent evidence for this distinction comes from the contrast between (77) and (78).

(77) weil die Tür auf ist.

because the door open is

'because the door is open.'

(78) * weil das Gold auf ist.

because the gold up is

'because the gold is up.'

Whereas in (77) auf is uncontroversially the semantic head of the predicate $(\mathrm{H})$ and hence, on our assumptions, bears the PREDICATE function, the ungrammaticality of (78) shows that the auf in auf=kaufen is not a possible semantic head of the predicate. It is consequently unable to bear the PREDICATE function. The parallelism between the topicalization facts in (72') - (74') and the predicative constructions with a copula in (77)

- (78) lends strong support to the claim that the topicalizability of pieces of predicates follows from the assumption that the function PREDICATE is only borne by the 
semantically dominant elements here. This correlation also explains why auf in (79) can be topicalized:

(79) [Auf] ist die Tür. open is the door

'The door is open.'

In summary, the distributions presented here indicate that (i) topicalizability cannot be simply stated in terms of a list of PVs which do or do not topicalize, but rather in terms of what type of relation a particular PV bears with respect to an associated verbal stem and (ii) those PVs which can topicalize and, by hypothesis, bear the PREDICATE function can also serve as PREDICATEs in predicative constructions. It remains only to be added that whereas it is necessary for the PV in these constructions to be interpretable as being semantically dominant, this is not sufficient. In fact, it is also necessary for the PV to be in potential paradigmatic contrast with another PV which could serve as an $\mathrm{H}$. This explains the difference in grammaticality between (80) and the earlier examples (72') (73'). Whereas auf=machen 'to open' (literally: 'to make open') and auf=treten 'to kick open' enter paradigmatic contrasts with $z u=$ machen 'to close' (literally 'to make shut') and $z u=$ treten 'to kick shut', there is no contrasting form $z u=b r e c h e n$ ' to break closed' for the form $a u f=b r e c h e n$ 'to break open' that occurs in (80).

(80) * [Auf] hat er die Tür gebrochen. open has he the door broken 'He broke the door open.'

We now turn to resultative constructions which are not expressed by PVs. Consider the following distributions:

(81a) [Zur Aufführung] hat das Theater das Stück gebracht. to performance has the theater the play brought

'The theater has presented the play.'

(81b) * [Gebracht] hat das Theater das Stück zur Aufführung. brought has the theater the play to performance 'The theater has presented the play.

(81c) [Zur Aufführung gebracht] hat das Theater das Stück. to perfomance brought has the theater the play 'The theater has presented the play.' 
These are exactly the distributions witnessed for the Type 3 PV V compositions reviewed before. In fact, resultative constructions in all of their standard expressions exhibit precisely the same behaviors with respect to topicalization. We present a representative example below:

(82a) Das Kind hat die Schuhe krumm gelaufen.

the child has the shoes crooked run

'The child has run her shoes crooked.'

(82b) [Krumm] hat das Kind die Schuhe gelaufen.

crooked has the child the shoes run

'The child has run her shoes crooked.'

$(82 c) *$ [Gelaufen] hat das Kind die Schuhe krumm run has the child the shoes crooked

'The child has run her shoes crooked.'

(82d) [Krumm gelaufen] hat das Kind die Schuhe. crooked run has the child the shoes

'The child has run her shoes crooked.'

In summary, by assimilating the class of Type $3 \mathrm{PV} \mathrm{V} \mathrm{compositions} \mathrm{to} \mathrm{resultatives}$ more generally we can explain (i) the similarity in the semantics between all of these sentence types and (ii) the identical topicalization of these categorially divergent constructions. In addition, it bears mention that the categorial $\mathrm{V}$ in all expression types of resultatives obeys the V2 constraint. Finally, the relatedness evident between these constructions makes it possible to treat them like other analytically expressed complex predicates which also contain major lexical categories rather than PVs. In the next section we turn to two types of such compositions which exhibit what have often been argued to be standard lexical effects, namely, function changes.

\subsection{Passive and Causative Complex Predicates - Function Changing Compositions}

In the case of type $3 \mathrm{PV} \mathrm{V}$ compositions (as well as resultatives in general) we have argued that the disjoint realization of the $\mathrm{C}$ and $\mathrm{H}$ of a complex predicate should be interpreted as follows: the categorial $\mathrm{V}$ is semantically subordinate to the secondary predicate of the composition, although it determines the categoriality of the composition. 
A reflex of its subordinate status is its inability to topicalize, since this option is reserved for the $\mathrm{C}$ (i.e. the bearer of the PREDICATE function) of the composition. In the present section we briefly explain the behaviors of the German passive and causative predicates repeated below:

Passive:

weil der Mann die Blumen geschenkt bekam. because the man the flowers given got 'because the man was given the flowers.'

Causative:

$$
\begin{aligned}
& \text { weil Peter den Wagen von dem Jungen waschen ließ. } \\
& \text { because Peter-NOM the car-ACC by the boy wash let } \\
& \text { 'because Peter had the car washed by the boy.' }
\end{aligned}
$$

Focusing for a moment on passives, we have argued elsewhere that passive formation in German requires the composition of a particular "auxiliary" verb (functioning as an $\mathrm{H}$ ) with a participle or infinitival form (functioning as an $\mathrm{C}$ ). ${ }^{23}$ Among other advantages of such an approach, it explains the differences in the thematic role assignments for the underlined SUBJ argument in the passive variant (83) above vs. the passive variant (85) below:

$$
\text { weil die Blumen dem Mann geschenkt wurden. }
$$
because the flowers the man given were

'because the flowers were given to the man.'

It should be observed that whereas the SUBJ argument corresponds to the beneficiary/recipient argument of schenken 'to give' in (83), it corresponds to the theme argument of this verb in (85). It needs only be observed that these associations of thematic roles with the SUBJ argument correlate in a principled fashion with the particular "auxiliary" verbs present in each variant of the passive construction: whereas the "auxiliary" bekommen requires a beneficiary/recipient argument when it functions as an independent verb with the meaning 'receive, obtain', the "auxiliary" werden requires a theme SUBJ when it functions as an independent active form with the meaning 'become.'

\footnotetext{
${ }^{23}$ For other approaches to the German Bekommen passive, see Haider (1984), Reis (1985), Wegener (1985) and references given there.
} 
For present purposes, we appear to be confronted with a complex passive predicate consisting of two pieces: the participle form functions as the $C$ (and bearer of the PREDICATE function), while the categorial verb functions as a semantically subordinate entity which modulates the mapping between thematic roles and grammatical functions for the passive predicate. Clearly, these assumptions about the nature of German passive constructions yield the desired distributions of topicalization for passive predicates.

In similar fashion, the German analytically expressed causative constructions are interpretable as consisting of a $C$ encoded by an infinitival form and an $\mathrm{H}$ which facilitates a reassignment of grammatical functions to the arguments of the $\mathrm{C}$ as well as contributing a causative meaning component to the complex predicate as a whole. The $\mathrm{H}$ element here performs a semantic role similar to the primitive CAUSE function which figured in the semantic representation of resultatives above and to the $H$ in passive predicates: like the $\mathrm{H}$ machen 'make' in the resultative auf=machen 'make open', lassen 'let, make' serves as the categorial head of the composition conferring the meaning CAUSE on the entire composition and like the $\mathrm{H}$ in passive predicates it facilitates a reassignment of grammatical functions for the causative predicate. Additionally, the categorial $\mathrm{V}$ of the complex predicate obeys the $\mathrm{V} 2$ constraint just as the $\mathrm{H}$ in resultative and passive constructions.

Given this analysis of causative predicates, it is to be expected that their component parts should behave like the component parts of resultative and passive predicates. This parallelism is indeed observed, as is the fact that the causative predicate as a whole bears the PREDICATE function, just like resultatives and passives.

\subsection{Predicate ADJ/NOM and Modal Complex Predicates}

So far we have seen that complex predicates which display clear lexical semantic alteration (Type 3 PV V compositions and resultatives more generally) and attendant function changes etc. as well as constructions which simply display function changes (passive and causative) conform to a unifying assumption that the categorial Vs are semantically dependent (i.e. they are H's), while the other element is semantically dominant and therefore an $\mathrm{C}$. This basic assumption is applicable to the remaining constructions examined here, namely, predicative constructions and constructions containing modals, despite the fact that they do not display any of the diagnostic properties ordinarily regarded as lexical effects. 
In this section we suggest that predicate nominal/adjective constructions as well as constructions containing various types of auxiliaries fit the profile of the complex predicates examined so far. Representative examples of the relevant types are repeated below:

weil Hans ein Busfahrer gewesen ist. because Hans a bus driver been is 'because Hans was a bus driver.'

(87) weil Hans krank gewesen ist. because Hans sick been is 'because Hans was sick.'

$$
\begin{aligned}
& \text { weil Hans singen können wollte. } \\
& \text { because Hans sing can wanted } \\
& \text { 'because Hans wanted to be able to sing.' }
\end{aligned}
$$

For these constructions the basic idea is that the semantically dominant element (i.e. the predicate adjective/nominal or infinitival form) contributes the argument structure to the composition, while the categorial $\mathrm{V}$ is semantically dependent. In the present cases the $\mathrm{C}$ is modified by morphosyntactic properties associated with the $\mathrm{H}$. The $\mathrm{H}$ serves to modulate the lexical meaning supplied by the $\mathrm{C}$ in various ways: it canonically conveys such information as aspect, modality, tense etc. and may determine certain semantic properties and case marking for arguments of the complex predicate.

Given these assumptions about the status of the pieces of these complex predicates, we can see why the topicalization behavior of these constructions parallels the distributions attested for other complex predicates.

\subsection{Idiomatic VPs}

Finally we turn to certain idiomatic VPs in an effort to explain why their $\mathrm{Y}$ elements, i.e. verbs, do not topicalize. Since idioms represent a disparate collection of entities with different syntactic behaviors and degrees of semantic transparency, we will limit ourselves to that type which participates in the topicalization pattern in which the verbal element cannot topicalize. ${ }^{24}$ Given this restriction, our observations are offered as suggestive.

\footnotetext{
${ }^{24}$ See Nunberg, Wasow and Sag (1994).
} 
We have assumed that what complex predicates share with idioms is that they both have lexical representations, i.e. they are both functional or lexical predicates. ${ }^{25}$ Given the assumptions we have made so far the explanation for the inability of the verb to topicalize in such constructions should follow from its not having the status of $\mathrm{C}$. That is, we are driven to assume that verbs in idioms are H's rather than C's. In fact, this assumption is compatible with usual beliefs about the errant meanings of idioms: entire idioms are associated with a meaning, their component pieces do not have the same meanings they ordinarily have as independent elements in other contexts. That is, these pieces fit the profile of defective lexical items characteristic of Hs. In the present instances, the verb can, accordingly, be interpreted as an $\mathrm{H}$ and as an $\mathrm{H}$ it cannot topicalize. Whereas the verb in these idioms still determines the function assignment for the OBJ complement, this complement is no longer a thematic argument of the verb. The verb is, in this sense, defective and thus an $\mathrm{H}$. Since its complement bears a grammatical function, specifically OBJ, it is correctly predicted to be topicalizable, since this is a topicalizable function in German.

The assumption that the $\mathrm{V}$ is defective in idioms of this type recalls those separable PV V compositions where neither the PV nor the V alone is topicalizable, (i.e. Type 2 above): the $\mathrm{V}$ in these $\mathrm{PV} \mathrm{V}$ constructions is not interpretable as bearing the PREDICATE function, but the whole composition is. Indeed, since neither piece in such compositions bears a grammatical function, only the entire composition, as the bearer of the PREDICATE function, can topicalize.

Independent evidence for the status of these verbs as H's may be derived from certain restrictions on nominalization. Let us assume that only Vs bearing the PREDICATE function can serve as bases for nominalization. For example, given the simple V zerstör'destroy' bearing the PREDICATE function we can create the nominal die Zerstörung (der Stadt ) 'the destruction (of the city)'. It follows that if the V in object idioms does not bear a PREDICATE function as we have assumed, then a sentence which is ambiguous between a literal and an idiomatic reading should lose the idiomatic reading under nominalization. We examine now how this prediction fares with (89) below which has two meanings:

\footnotetext{
${ }^{25}$ The formal identification of complex predicate and idiomatic expressions is dramatically evident in Mandarin Chinese as analyzed in Chen (In press). Both resultative complex predicates and the VP in object idioms are treated as single domains for lexical tone sandhi. Non-idiomatic VPs, in contrast, are treated as multiple domains.
} 
weil Hans den Vogel abgeschossen hat.

because Hans the bird shot-off has

LIT: 'because Hans shot the bird off.'

IDIOM: 'because Hans stole the show.'

As can be seen in (90), the idiomatic reading is lost in the nominal form:

[Der Abschuß des Vogels] wurde Hans überlassen.

the off-shooting (of) the bird was Hans left-to

LIT: 'The shooting off of the bird was left to Hans.'

*IDIOM: 'The stealing of the show was left to Hans.'

The observation that there is a restriction in English for nominalizations of verbs within idioms was made originally by Weinreich (1969). This can be illustrated as follows under the standard assumption that the underlined words in (91) and (92) are verbal and nominal respectively:

(91) Moe's biting the dust pleased all his detractors

(92) *Moe's biting of the dust pleased all his detractors (on an idiomatic

interpretation)

Whereas Weinreich stipulates the inability of such Vs to nominalize, we hypothesize that this behavior is derivable from a general property, namely, the absence of a PREDICATE function associated with these verbs. On our account the inability to topicalize and the inability to participate in nominalization consequently share the same explanation.

There is a point worth making concerning the difference between the present analysis and semantically based analyses of idioms with respect to the topicalizable OBJECT NP: we are not claiming that the topicalized NP of an idiom has a meaning in the manner necessary for compositional accounts, but rather we need only claim that the relevant NP bears a topicalizable function, i.e. OBJECT in this instance, which can be referenced and thereby licenses topicalization.

Finally, we have previously observed that standard FU neither predicts the possibility that heads of functions can topicalize on their own nor the fact that this behavior distinguishes non-idiomatic from idiomatic VPs. Given that VP idioms are assimilated to the class of complex predicates and that association with a PREDICATE function licenses topicalization, the observed behaviors follow on the present account. In particular, since the V of non-idiomatic VPs is construable as C, and accordingly bears the PREDICATE function, it is topicalizable. In contrast, the V in idiomatic VPs resembles the $\mathrm{H}$ of complex predicates and accordingly is predicted to be prohibited from 
topicalizing. In summary, the revised version of FU not only accounts for why heads of certain functions can topicalize, but provides an explanation for why idioms and nonidiomatic VPs behave precisely as they do.

In all of the preceding sections we have motivated the association of the PREDICATE function with certain pieces of functional or lexical words. This has been facilitated by the assumption that certain analytic expressions of lexical representations can be interpreted in terms of a distinction between a semantically dominant element (the CORE) and a semantically dependent element (the HEAD).

\section{Conclusions}

In this paper we have argued that the PREDICATE function is a property associated with lexical representations. Specifically, it is associated with an entire lexical representation for a predicator or with some piece of the predicator. Given the distinction between CORE and HEAD developed previously, this yields three possible alignments of PREDICATE with lexical representations. If the lexical representation is expressed by an element such as a single verb, the CORE and HEAD coexist in a single morphological unit and this object is associated with the PREDICATE function. If, however, the lexical representation is expressed by multiple independent elements, then the PREDICATE function is associated with either the CORE and HEAD jointly or with the CORE alone.

We have examined 10 different types of German verbal constructions and argued for a unified approach to explain their behaviors with respect to topicalization in terms of the concepts 'complex predicate,' 'PREDICATE function,' and 'Functional Uncertainty.' The function assignments we have argued for are repeated below:

\section{Summary of Distributions \\ (Attributions of Function)}

(i) er-ziehen

(ii) an=rufen

(iii) auf=machen

(iv) geschenkt bekommen

(v) waschen lassen

(vi) krank sein

(vii) ein Busfahrer sein

(viii) singen können

(ix) den Vogel abschießen
X

$*$

$*$

PRED

PRED

PRED

PRED

PRED

PRED

OBJ
Y

*

$*$

$*$

*

$*$

$*$

*

$*$

*
$\mathrm{X}+\mathrm{Y}$

PRED

PRED

PRED

PRED

PRED

PRED

PRED

PRED

PRED 

(x)
den Apfel essen
OBJ
PRED
PRED

All cases but the last one were analyzed as complex predicates independent of their various phrase structural realizations. The distribution of the PRED function was arrived at with the help of the following principle:

The PREDICATE function in German is associated with the CORE of a semantically compositional analytic predicate as well as with the (complex) predicate as a whole. It is never associated with the HEAD of a predicate alone.

All the $\mathrm{X}+\mathrm{Y}$ compositions in (95) are predicted to be PREDs, in the first nine cases because they are complex predicates and in case $(95 \mathrm{x})$ because it is natural to assume that the predicate essen can percolate its PRED function to its phrasal projection. No part of the complex predicates in (95i-ii) qualifies as a PRED because the meaning of the complex predicate is non-compositional. This is also the reason why the verb in case (95ix) is not a PRED, even though nothing prevents the NP it co-occurs with from bearing the OBJ function. That the leftmost members in (95iii-viii) are PREDs follows from the assumption that this function is accessible only to the semantically dominant head of a complex predicate, in the sense that a part of a complex predicate that is semantically selected by another dominates the selector.

We emphasize that there are two basic assumptions which underlie the sort of analysis presented here: (i) a function based account of topicalization and (ii) a distinction between different aspects of wordhood, specifically, between functional or lexical words and their formal expression. Both of these assumptions seem to derive strong empirical support from the paradigms presented in this paper.

\section{REFERENCES}

Ackerman, Farrell. 1984. Verbal modifiers as argument taking predicates: complex predicates as predicate complexes. Groninger Arbeiten zur Germanistischen Linguistik. 23-71. 
Ackerman, Farrell. 1987. Miscreant morphemes . Unpublished Ph. D. Dissertation. UC Berkeley.

Ackerman, Farrell and Phil LeSourd. 1997. Toward a theory of phrasal predicates. In P. Sells et. al. eds. Complex predicates, ed. by Peter Sells et al. CSLI Publications: Stanford University.

Ackerman, Farrell and Gert Webelhuth. 1993. Complex predicates and wordhood: passive constructions in German. Papers from the 28th regional meeting of the Chicago Linguistic Society 1992: Volume 1, the main session, 554-564. Chicago: Chicago Linguistic Society.

Ackerman, Farrell and Gert Webelhuth. 1998. A theory of predicates. Stanford University: CSLI Publications.

Alsina, Alex. 1993. The monoclausality of causative constructions in Romance. Unpublished manuscript. Stanford University.

Andrews, Avery and Christopher Manning. 1993. Information spreading and levels of representation in LFG. Technical Report CSLI-93-176. CSLI. Stanford University.

Andrews, Avery and Chris Manning. In press. Complex predicates and information spreading in LFG. Stanford: CSLI Publications.

Anderson, Stephen. 1992. A-morphous morphology. Cambridge, England: Cambridge University Press.

Baker, Mark. 1988. Incorporation: a theory of grammatical function changes. Chicago: University of Chicago Press.

Bierwisch, Manfred. 1990. Verb cluster formation as a morphological process. Yearbook of Morphology 3.173-199.

Bresnan, Joan. 1982. Control and complementation. The mental representation of grammatical relations, ed. by Joan Bresnan, 282-390. Cambridge, Massachusetts: MIT Press.

Bresnan, Joan. Forthcoming. Lexical functional syntax. To be published by Blackwells Publishers.

Bresnan, Joan and Jonni Kanerva. 1989. Locative inversion in Chichewa: A case study of factorization in grammar. Linguistic Inquiry 20.1-50.

Bresnan, Joan and Sam A. Mchombo. 1987. Topic, pronoun and agreement in Chichewa. Language 63.741-782.

Bresnan, Joan and Sam A. Mchombo. 1995. The lexical integrity principle: evidence from Bantu. Natural Language and Linguistic Theory 13.181-254.

Butt, Miriam, Maria-Eugenia Niño, and Frederique Segond. 1996. Multilingual processing of auxiliaries in LFG. Natural Language Processing and Speech 
Technology: Results of the 3rd KONVENS Conference, ed. by Dafydd Gibbon, 111-122. Berlin: Mouton De Gruyter.

Chen, Matthew. In press. Tone sandhi. Cambridge: Cambridge University Press.

Dalrymple, Mary. 1993. The syntax of anaphoric binding. Stanford: CSLI Publications.

Dalrymple, Mary et. al. 1992. Relating projections. Unpublished manuscript. Xerox.

Davies, William and Carol Rosen. 1988. Unions as multi-predicate clauses. Language 64.52-88.

den Besten, Hans. 1985. The ergative hypothesis and free word order in Dutch and German. Studies in German grammar, ed. by J. Toman, 23-64. Dordrecht: Foris Publications.

Di Sciullo, Anna Maria and Edwin Williams. 1987. On the definition of word. Cambridge, Massachusetts: MIT Press.

Dixon, D.M.W. 1976. Grammatical categories in Australian languages. Linguistic Series 22. New Jersey: Humanities Press.

Dowty, David. 1979. Word meaning and Montague Grammar. Dordrecht: Reidel.

Evers, Arnold. 1975. The transformational cycle in German and Dutch. Unpublished Ph.D. dissertation. University of Utrecht. The Netherlands.

Falk, Yehuda N. 1984. The English auxiliary system: A lexical-functional analysis. Language 60(3).483-509.

Foley, William A. and Robert D. Van Valin, Jr. 1984. Functional syntax and universal grammar. Cambridge: Cambridge University Press.

Goldberg, Adele Eva. 1995. Argument structure constructions. Chicago: University of Chicago Press.

Grimshaw, Jane. 1982. On the lexical representation of Romance reflexive clitics. The mental representation of grammatical relations, ed. by Joan Bresnan, 87-148. Cambridge, MA: The MIT Press

Grimshaw, Jane and Armin Mester. 1988. Light verbs and theta marking. Linguistic Inquiry 19.205-232.

Haegeman, Liliane and Henk van Riemsdijk. 1986. Verb projection raising, scope and the typology of rules affecting verbs. Linguistic Inquiry 17.417-66.

Haider, Hubert. 1981. Dependenzen und Konfigurationen. Groninger Arbeiten zur Germanistischen Linguistik 21.1-59.

Haider, Hubert. 1984. Mona Lisa lächelt stumm - über das sogenannte Rezipientenpassiv. Linguistische Berichte 89.32-42.

Haider, Hubert. 1985. The case of German. Issues in German grammar, ed. by . J. Toman, 65-101. Dordrecht: Foris Publications. 
Holloway-King, Tracy. 1995. Configuring topic and focus in Russian. Stanford: CSLI Publications.

Inkelas, Sharon. 1989. Prosodic constituency in the lexicon . Unpublished Ph.D. dissertation. Stanford University.

Jackendoff, Ray. 1987. Consciousness and the computational mind. Cambridge, Mass.: MIT Press.

Jackendoff, Ray. 1997. The architecture of the language faculty. Cambridge, Mass.: MIT Press.

Kaplan, Ron. 1989. The formal architecture of Lexical-Functional Grammar. Journal of Information Science and Engineering 5.305-322. Reprinted in Formal issues in Lexical -Functional Grammar, ed. by M. Dalrymple. 1996, 3-23. Stanford: CSLI Publications.

Kaplan, R. M. and Annie Zaenen. 1989. Long distance dependencies, constituent structure and functional uncertainty. Alternative conceptions of phrase structure, ed. by M. Baltin and T. Kroch, 17-42. Chicago: Chicago University Press.

Kratzer, Angelika. 1995. The event argument. Unpublished manuscript. University of Massachusetts. Amherst.

Lehiste, I. 1964. Compounding as a phonological process. Proceedings of the 9th International Conference of Linguists, ed. by Horace Lust. The Hague: Mouton.

Levin, Beth and Malka Rappaport-Hovav. 1994. Unaccusativity. Cambridge, Mass.: MIT Press.

Matthews, Peter. 1972. Inflectional morphology. London and New York: Cambridge University Press.

Matthews, Peter. 1974. Morphology: an introduction to the theory of word structure. London and New York: Cambridge University Press.

Matsumoto, Yo. 1996. Complex predicates in Japanese: A syntactic and semantic study of the notion 'word'. Stanford: CSLI Publications.

Mohanan, K. P. 1982. Grammatical relations in Malayalam. The mental representation of grammatical relations, ed. by Joan Bresnan. Cambridge Mass.: MIT Press.

Mohanan, Tara. 1990/1994. Arguments in Hindi. Stanford: CSLI Publications.

Mohanan, Tara. 1995. Wordhood and lexicality: noun incorporation in Hindi. Natural Language and Linguistic Theory 13(1).75-134.

Nordlinger, Rachel. 1998. Constructive case: evidence from Australia. Stanford: CSLI Publications.

Nunberg, Geoffrey, Ivan Sag, and Tom Wasow. 1994. Idioms. Language 70.491-538. 
Perlmutter, David. 1979. Predicate: A grammatical relation. Linguistic Notes from La Jolla. Distributed by the Department of Linguistics at the University of California at San Diego.

Pollard, Carl and Ivan Sag. 1994. Head-Driven Phrase Structure Grammar. Stanford/Chicago: CSLI Publications/University of Chicago Press.

Reis, Marga. 1985. Mona Lisa kriegt zuviel - vom sogenannten Rezipientenpassiv im Deutschen. Linguistische Berichte 46.140-155.

Rosen, Carol. 1988. Italian evidence for multi-predicate clauses. Grammatical relations: a cross-theoretical perspective, ed. by K. Dziwirek et al., . 415-444. Stanford/Chicago: CSLI Publications/University of Chicago Press.

Rosen, Sara. 1989. Argument structure and complex predicates. Unpublished Ph.D. dissertation. Brandeis University.

Sells, Peter, Annie Zaenen, and Draga Zec. 1987. Reflexivization variation: relations between syntax, semantics, and lexical structure. Working papers in grammatical theory and discourse structure, vol. I: interactions of morphology, syntax, and discourse, ed. by Masayo Iida. et. al., 169-238. Stanford: CSLI Publications. CSLI Lecture Notes, number 11.

Sadock, Jerrold. 1991. Autolexical syntax. Chicago: University of Chicago Press.

Simpson, Jane. 1983. Aspects of Warlpiri morphology and syntax. Unpublished Ph.D. dissertation. MIT. Department of Linguistics and Philosophy.

Stiebels, Barbara and Dieter Wunderlich. 1994. Morphology feeds syntax: the case of particle verbs. Linguistics 32.913-968.

Webelhuth, Gert. 1992. Principles and parameters of syntactic saturation. Oxford: Oxford University Press.

Webelhuth, Gert .1994. On the universal and language-particular components of the German passive. Proceedings of the Eastern States Conference on Linguistics, 330341. Ithaca: Cornell University. The Department of Modern Languages and Linguistics.

Wegener, Heide. 1985. Er bekommt widersprochen - Argumente für die Existenz eines Dativpassivs im Deutschen. Linguistische Berichte 96.127-139.

Weinreich, Uriel. 1969. Problems in the analysis of idioms. On Semantics, ed. by W. Labov and B. Weinreich . Philadelphia: University of Pennsylvania Press.

Zhirmunskij, V. M. and O.P. Sunik. 1963. The morphological structure of words in languages of different types. Moscow: Akademii Nauk SSSR.

Zwicky, Arnold. 1990. Syntactic words and morphological words, simple and composite.

Yearbook of Morphology 3.201-216. 
